\title{
Evolução do estado nutricional de pacientes com insuficiência renal crônica e hiperparatireoidismo secundário submetidos a paratireoidectomia
}

\author{
Bárbara Santarosa Emo Peters
}

Dissertação apresentada ao programa de Pós-Graduação em Saúde Pública da Faculdade de saúde Pública da universidade de São Paulo para obtenção do título de Mestre em Saúde Pública.

Área de concentração: Nutrição

Orientadora: Profa. Dra. Lígia A. Martini

São Paulo 
Autorizo exclusivamente para fins acadêmicos e cientificos, a reprodução total ou parcial desta dissertação, por processos fotocopiadores. Ao usa-lo cite a fonte.

Assinatura:

Data:

$$
4582712005 \text { dec. }
$$


"Quem nada conhece, nada ama. Quem nada pode fazer, nada compreende. Quem nada compreende, nada vale. Mas quem compreende também ama, observa, vê... Quanto mais conhecimento houver inerente numa coisa, tanto maior o amor... Aquele que imagina que todos os frutos amadurecem ao mesmo tempo, como as cerejas, nada sabe a respeito das uvas." 
Dedico esta dissertação

A Ligia, por todos os ensinamentos, pela confiança, e principalmente pela amizade;

Ao Luís, meu amado marido, pela paciência, incentivo e amor;

A minha mãe, por continuar sendo a mãe mais sensacional do universo sideral. 


\section{Agradeço}

A todos os pacientes do ambulatório de osteodistrofia renal, pelo grande aprendizado que me proporcionaram, e por tornar esta tese realidade;

As Dras. Vanda Jorgetti e Rosa Moysés, pelos vários conhecimentos compartilhados;

Aos médicos (as), enfermeiros (as), auxiliares de enfermagem, secretários (as), recepcionistas, faxineiros (as) do ambulatório de osteodistrofia renal, por toda ajuda com os pacientes e "papeladas" durante os dias de ambulatório;

A aluna de iniciação científica Tatiana e a nutricionista Karin, pela grandiosa ajuda com os pacientes do ambulatório de osteodistrofia renal;

A Luciene e a Fabiana, por me ensinarem várias vezes a como utilizar os equipamentos do laboratório de doenças ósseas;

A Maria Aparecida Dalboni (Bak), pelos ensinamentos sobre o ELISA, e por disponibilizar seu tempo e o laboratório, obrigada pelo carinho e atenção;

Ao professor Wolney Lisboa Conde, por ampliar meus conhecimentos sobre antropometria; 
A Ângela Pereira da Silva, por elucidar com toda a paciência do mundo as freqüentes e inúmeras dúvidas;

A todos os funcionários do departamento de nutrição, pelos auxilios indispensáveis;

Ao Conselho Nacional de Desenvolvimento Cientifico e TecnológicoCNPq, pelo apoio financeiro;

As colegas de pós-graduação, Priscila, Juliana, Silvia, Natacha, professora Bethzy, professora Nágila e professora Regina por compartilhar conhecimentos especificos e momentos de descontração;

As amigas Patrícia e Luana, por todos os momentos. 
Resumo 


\section{RESUMO}

Peters, BSE. Evolução do Estado Nutricional de Pacientes com Insuficiência Renal Crônica e Hiperparatireoidismo Secundário Submetidos a Paratireoidectomia. São Paulo; 2004 [Dissertação de mestrado - Faculdade de Saúde Pública da USP].

Objetivo: Sendo o hiperparatireoidismo um agravante para desnutrição em pacientes com Insuficiência Renal Crônica (IRC), o objetivo deste trabalho foi avaliar o estado nutricional de pacientes com IRC em programa de hemodiálise com Hiperparatireoidismo Secundário (HPT2) submetidos a Paratireoidectomia (PTX). Casuística e métodos: $O$ estudo foi realizado no Ambulatório de Osteodistrofia Renal do ICHC/FMUSP. Foram acompanhados 15 pacientes adultos, de ambos os sexos, com idade média de $43,4 \pm 12,7$ anos. Os dados para avaliação nutricional e bioquímica foram coletados antes e após 6 meses de realização da PTX. Os participantes realizaram diário alimentar de 3 dias para a análise da ingestão de energia, proteína, cálcio e fósforo; medidas antropométricas, peso, altura, Índice de Massa Corporal (IMC) e Impedância Bioelétrica (BIA); e parâmetros bioquímicos nutricionais e do metabolismo ósseo como proteína total, albumina, uréia, creatinina, proteína $C$ reativa, cálcio e fósforo sérico, fosfatase alcalina total, fração óssea da fosfatase alcalina, vitamina $D$ e paratormônio intacto (iPTH). Resultados: Não houve alteração significante nos valores médios de energia, ingestão de carboidratos, lipídeos, proteínas, e fósforo após a cirurgia, somente a ingestão média de cálcio aumentou significantemente após a PTX (de 382,2 $\pm 209,6 \mathrm{mg}$ para $656,6 \pm 313,8 \mathrm{mg}$; $\mathrm{p}<0,05$ ). O peso e IMC também não apresentaram alteração durante o estudo. Quanto aos dados obtidos pela BIA, a gordura corporal (GC), massa magra (MM), água corporal total ( $\mathrm{ACT}$ ), e a água extracelular (AEC) não apresentaram alteração significativa após os 6 meses da cirurgia; entretanto, o ângulo de fase $(\phi)$ e a reactância $(X c)$ aumentaram significantemente após a PTX $(5,0 \pm 1,4$ graus para $5,6 \pm 1,3$ graus; $44,1 \pm 15,6 \mathrm{Ohm}$ para $57,1 \pm 14,4 \mathrm{Ohm}$, respectivamente; $p<0,05)$. Foi encontrada 
correlação negativa entre o iPTH e a GC $(r=-0,69, p=0,014)$ apenas antes da PTX. Como esperado, houve melhora significante no fósforo sérico (Ps), fosfatase alcalina total (Fat), fração óssea da fosfatase alcalina (FAfo) e iPTH após a PTX $(6,7 \pm 1,8$ para $4,5 \pm 1,5 \mathrm{mg} / \mathrm{dl} ; 542,2 \pm 835,4$ para $111,9 \pm 68,2 \mathrm{U} / \mathrm{l} ; 135,6 \pm 230,1$ para $24,5 \pm 16,0 \mathrm{U} / \mathrm{l} ; 1221,6 \pm 685,1$ para $153,1 \pm 189,2 \mathrm{pg} / \mathrm{ml}$, respectivamente; $p<0,05)$, e também na albumina e proteína total. Não houve alteração quanto ao cálcio sérico total, vitamina $D$ e proteína $C$ reativa. Conclusão: No presente estudo foram observados benefícios da PTX para o estado nutricional de pacientes com altos niveis de iPTH. Houve melhora na composição corporal de acordo com os dados da BIA, melhora nos parâmetros bioquímicos relacionados ao estado nutricional e ao metabolismo ósseo, e, além disso, verificou-se ausência do efeito negativo do PTH na gordura corporal. 


\section{Abstract}




\section{ABSTRACT}

Peters, BSE. Nutritional Evaluation in Chronic Renal Failure Patients with Secondary Hyperparathyroidism after Parathyroidectomy. São Paulo; 2004. [Master in Science - School of Public Health / São Paulo University].

Purpose: Considering the negative nutritional effects of the hyperparathyroidism in Chronic Renal Failure (CRF) patients, this study was undertaken to evaluate the nutritional status of hemodialysis CRF patients with Secondary Hyperparathyroidism submitted to Parathyroidectomy (PTX). Methods: The study was carried out in the renal osteodystrophy out patient clinic at the ICHC/FMUSP. Fifteen adult patients, mean age $43.4 \pm 12.7$ years old, both gender, were evaluated. Before and 6 months after PTX the nutritional and biochemical evaluation were performed. It includes, tree day dietary records, in order to measure mean energy, protein, calcium and phosphorus intake; anthropometric measures as such as weight, height, body mass index (BMI) and bioelectrical impedance (B|A); and biochemical markers of nutritional status (albumin and total protein), bone metabolism (calcium, phosphorus, total and bone alkaline phosphatase, vitamin D and intact parathyroid hormone-iPTH), creatinine, urea and C-reactive protein. Results: No significant differences were observed in mean energy, carbohydrates, total fat, protein and phosphorus after surgery. There was a significant increase in calcium intake after PTX $(382.3 \pm 209.6 \mathrm{mg}$ to $656.6 \pm 313.8$ $\mathrm{mg} ; \mathrm{p}<0.05)$. The mean weight and BMI did not differ after surgery. No significant changes were observed in the BIA measurements, total body fat (TBF), lean body mass (LBM) and total body water (TBW). However the phase angle $(\phi)$ and reactance $(X c)$ significantly increased after $\mathrm{PTX}(5.0 \pm 1.4$ degree to $5.6 \pm 1.3$ degree; $44.1 \pm 15.6 \mathrm{Ohm}$ to $57.1 \pm 14.4 \mathrm{Ohm}$, respectively). Furthermore, there was a negative correlation between iPTH and TBF $(r=-0.69, p<0.05)$ before PTX. The biochemical parameters of bone metabolism decrease after PTX, phosphorus, total alkaline phosphatase, bone alkaline phosphatase and $\mathrm{PTH}(6.7 \pm 1.8 \mathrm{mg} / \mathrm{dl}$ to 
$4.5 \pm 1.5 \mathrm{mg} / \mathrm{dl} ; 542.2 \pm 835.4 \mathrm{U} / \mathrm{l}$ to $111.9 \pm 68.2 \mathrm{U} / / ; 135.6 \pm 230.1 \mathrm{U} / \mathrm{l}$ to $24.5 \pm$ $16.0 \mathrm{U} / \mathrm{l} ; 1221.6 \pm 685.1 \mathrm{pg} / \mathrm{ml}$ to $153.1 \pm 189.2 \mathrm{pg} / \mathrm{ml}$, respectively; $p<0.05)$. The mean albumin $(3.9 \pm 0.4 \mathrm{~g} / \mathrm{dl}$ to $4.2 \pm 0.6 \mathrm{~g} / \mathrm{dl}$; $p<0.05)$ significantly increased, and no changes were observed in total calcium, vitamin D and C-reactive protein. Conclusion: The study presented the positive effects of the PTX on the nutritional status of CRF patients with higher PTH levels. The anthropometric and biochemical data of the nutritional status and bone metabolism improved, and no negative effect of PTH on TBF was observed after surgery.

Descriptors: chronic renal insufficiency, renal osteodystrophy, secondary hyperparathyroidism, body composition, food intake. 
Índice 


\section{INDICE}

1. INTRODUÇÃO 01

1.1 Função Renal 01

$\begin{array}{ll}1.2 \text { Osteodistrofia Renal } & 02\end{array}$

1.3 Hiperparatireoidismo Secundádio (HPT2) 02

1.4 Fisiopatogenia do HPT2 03

$\begin{array}{ll}\text { 1.4.1 Hipocalcemia } & 03\end{array}$

1.4.2 Retenção de Fósforo $\quad 04$

1.4.3 Diminuição dos Níveis Séricos de Calcitriol 04

1.4.4 Resistência Esquelética à Ação Calcêmica do PTH 05

$\begin{array}{ll}1.5 \text { Tratamento do HPT2 } & 05\end{array}$

1.5.1 Tratamento Clínico do HPT2 05

$\begin{array}{ll}\text { 1.5.2 Tratamento Cirúrgico do HPT2 } & 07\end{array}$

$\begin{array}{ll}1.6 \text { Nutrição na IRC e no HPT2 } & 08\end{array}$

1.7 Avaliação Nutricional de Pacientes com IRC e HPT2 10

2. OBJETIVOS 15

2.1 Objetivo Geral 15

2.2 Objetivos Especificos 15

3. CASUÍSTICA E MÉTODOS 16

3.1 Pacientes 16

$\begin{array}{ll}3.2 \text { Protocolo de Estudo } & 17\end{array}$

$\begin{array}{ll}\text { 3.2.1 Avaliação da ingestão alimentar } & 18\end{array}$

$\begin{array}{ll}\text { 3.2.2 Medidas antropométricas } & 18\end{array}$

3.2.3 Medidas bioquímicas $\quad 21$

3.2.4 Avaliação do metabolismo ósseo 21

3.3 Análise Estatística $\quad 22$

3.4 Comitê de Ética 22

4. RESULTADOS 23

4.1 Características gerais 23

4.2 Ingestão alimentar 23

$\begin{array}{ll}4.3 \text { Medidas antropométricas } & 26\end{array}$ 
4.4 Ingestão alimentar e antropometria $\quad 30$

4.5 Exames bioquímicos 31

4.6 Exames bioquímicos e ingestão alimentar 35

4.7Exames bioquímicos e composição corporal 36

5. DISCUSSÃO $\quad 40$

5.1 Ingestão alimentar $\quad 40$

5.2 Antropometria $\quad 42$

5.3 Parâmetros bioquímicos 446

5.4 Paratormônio e estado nutricional 53

6. CONCLUSÕES

7. REFERÊNCIAS BIBLIOGRÁFICAS

ANEXOS I

Anexo 1- Termo de consentimento I

Anexo 2- Formulário de Registro Alimenta II

Anexo 3- Aprovação do projeto de pesquisa pelo COEP III 


\section{Lista de Tabelas}




\section{LISTA DE TABELAS}

Tabela 1. Características gerais dos pacientes estudados

Tabela 2. Valores médios de altura, peso seco e IMC dos pacientes estudados, antes e após a PTX

Tabela 3. Classificação dos pacientes antes e após PTX, segundo o IMC 27

Tabela 4. Estimativa da componentes corporais dos pacientes em HD com HPT2, pela análise da impedância bioelétrica antes e após PTX 27

Tabela 5. Parâmetros vetoriais da impedância bioelétrica e valores do ângulo de fase antes e após a PTX

Tabela 6. Correlação entre dados de ingestão alimentar e antropometria, em pacientes em HD com IRC e HPT2, antes da PTX

Tabela 7. Correlação entre dados de ingestão alimentar e antropometria, em pacientes em HD com IRC e HPT2, após os 06 meses de PTX 31

Tabela 8. Exames bioquímicos relacionados à eficiência da diálise, estado nutricional e inflamação, de pacientes em HD com IRC e HPT2, antes e após a PTX

Tabela 9. Exames bioquímicos relacionados ao metabolismo ósseo

Tabela 10. Correlação entre marcadores bioquímicos do metabolismo ósseo de pacientes em HD com IRC e HPT2, antes e após a PTX

Tabela 11. Correlação entre exames bioquímicos e ingestão alimentar de pacientes em HD com IRC e HPT2, antes da PTX

Tabela 12. Correlação entre exames bioquímicos e ingestão alimentar de pacientes em HD com IRC e HPT2, após 06 meses da PTX

Tabela 13. Correlação entre exames bioquímicos e dados da composição corporal dos pacientes estudados, antes da PTX

Tabela 14. Correlação entre exames bioquímicos e dados da composição corporal de pacientes em HD com IRC e HPT2, após 06 meses da PTX 


\section{Lista de Figuras}




\section{LISTA DE FIGURAS}

Figura 1. Esquema representativo da colocação dos eletrodos distal e proximal, para a realização da impedância bioelétrica 20

Figura 2. Ingestão de Ca e P dos pacientes com IRC e HPT2 antes e após a PTX

Figura 3. Ingestão de macronutrientes de pacientes com IRC e HPT2 antes e após a PTX 24

Figura 4. Porcentagem de adequação da ingestão alimentar em relação às recomendações pelo K/DOQI 26

Figura 5. Gráfico RXc-escore com elipses de $95 \%, 75 \%$ e $50 \%$ de tolerância em pacientes com IRC e HPT2 antes e após a PTX

Figura 6. Correlação entre iPTH e Gordura Corporal (GC) de pacientes em HD com IRC e HPT2, antes da PTX

Figura 8. Correlação entre iPTH e Gordura Corporal (CG) de pacientes em HD com IRC e HPT2, após 06 meses da PTX 
Introdução 


\section{INTRODUÇÃO}

\subsection{Função Renal}

O rim desempenha um papel fundamental na homeostase do organismo, ou seja, para que ocorra o equilíbrio é necessário que haja uma constância do volume de líquidos, de nutrientes e dos elementos que compõem o meio interno ${ }^{94}$. Uma disfunção deste órgão, como a insuficiência renal crônica (IRC), pode levar à uremia, síndrome tóxica, com profundas modificações na composição química dos líquidos do organismo ${ }^{7}$.

A IRC consiste na perda progressiva e irreversível da função renal (glomerular, tubular e endócrina), de tal forma que, em sua fase mais avançada, os rins não conseguem mais manter a normalidade do meio interno do paciente. Neste momento inicia-se a remoção de líquidos e de produtos tóxicos do metabolismo através de tratamentos dialíticos, como a hemodiálise ${ }^{59}$.

$\mathrm{Na}$ IRC, a perda de funções como manutenção do equilíbrio hidroeletrolítico e ácido-básico, excreção de catabólitos e função reguladora hormonal desencadeiam conseqüências adversas para o paciente tais como anemia, deficiência imunológica, desordens no metabolismo protéico, de lipídeos e carboidratos, doenças ósseas, além de complicações gastrointestinais (anorexia, vômitos, etc.), cardiovasculares e comprometimento severo do estado nutricional 7,51 .

Segundo o novo censo 2003/2004 da Sociedade Brasileira de Nefrologia, existem hoje 58.989 pacientes que recebem tratamento dialítico (89,25\% em hemodiálise) em um conjunto de 257 unidades hospitalares, 110 unidades satélite intra-hospitalares e 208 unidades satélite extra-hospitalares. Em relação ao Censo de $2202 / 2003$, houve um aumento de $6,75 \%$ no número de pacientes em tratamento dialítico ${ }^{120}$. 


\subsection{Osteodistrofia Renal}

O termo osteodistrofia renal (OR), proposto por Liu \& Chu em $1943^{70}$, é utilizado para definir as alterações esqueléticas secundárias às modificações do metabolismo do cálcio e do fósforo que acometem pacientes com insuficiência renal crônica (IRC), e compreende um espectro de alterações clínico-laboratoriais, variando desde quadros assintomáticos até doenças ósseas graves. Nos últimos anos, sua prevalência vem crescendo devido ao aumento da sobrevida dos pacientes com IRC, causado principalmente pela melhoria das técnicas de diálise 49.

A biópsia óssea é considerada o método diagnóstico mais preciso, permitindo diferenciar entre os diversos tipos de $O R{ }^{27,56}$. A taxa de formação óssea, parâmetro obtido da análise histomorfométrica, permite classificar a OR em doenças de alta e baixa remodelação óssea ${ }^{71}$. As doenças de alta remodelação, decorrentes do hiperparatireoidismo secundário (HPT2), são representadas pela osteíte fibrosa, e as de baixa remodelação pela osteomalácia e doença óssea adinâmica. Um estado intermediário entre a alta e a baixa remodelação é conhecido como doença mista ${ }^{81,110}$.

\subsection{Hiperparatireoidismo secundário (HPT2)}

Estima-se que cerca de $50 \%$ dos pacientes mantidos em diálise desenvolvem HPT2 ${ }^{107}$. Esta é uma complicação freqüente em pacientes com IRC, e se caracteriza pela hiperplasia das glândulas paratireóides e hipersecreção de paratormônio $(\mathrm{PTH}){ }^{35,37,40,98,114}$.

O hiperparatireoidismo secundário exibe quadro clínico multiforme em conseqüência de complexas alterações fisiopatológicas ${ }^{121}$. Podem ocorrer dores ósseas e musculares, prurido, calcificação de partes moles, calcifilaxia, fraturas, deformidades ósseas e osteoclastomas ("tumores marrons"), perda do apetite, anormalidade no paladar e perda de peso, em intensidade variável ${ }^{10,63,72}$. 
Sua etiopatogenia é multifatorial, na qual destacam-se a participação da hipocalcemia, da retenção de fósforo, da diminuição dos níveis de calcitriol e da resistência esquelética à ação do paratormônio (PTH). A compreensão destes fatores se faz necessária para o desenvolvimento de medidas terapêuticas que permitam o controle desta importante patologia. $O$ aumento da morbidade $e$ mortalidade de pacientes com HPT2 em diálise, ocorre devido aos efeitos deletérios do PTH no esqueleto, e também pelas conseqüências sistêmicas, principalmente no que se refere ao aparelho cardiovascular.

\subsection{Fisiopatogenia do HPT2}

\subsubsection{Hipocalcemia}

Pacientes com IRC freqüentemente desenvolvem hipocalcemia, o que é explicada por vários fatores. Entre eles, a menor ingestão de cálcio, hiperfosfatemia, déficit de calcitriol e resistência esquelética à ação calcêmica do PTH ${ }^{32,98,112,113}$.

Como está bem estabelecido, a concentração extracelular do cálcio é a maior determinante da secreção de $\mathrm{PTH}^{3,77,119}$. Embora a hipercalcemia não seja capaz de suprimir completamente a secreção de PTH, uma correlação negativa entre o cálcio extracelular e o hormônio tem sido bem demonstrada de forma clínica e experimental ${ }^{3}$.

A expressão do RNA-mensageiro do PTH também é regulada pelo cálcio, sendo a hipocalcemia um estímulo para o seu aumento. A hipocalcemia estimula a produção de PTH respeitando três estágios:

1) secreção imediata do PTH estocado, o qual ocorre em frações de segundos mediante a ação direta do cálcio nas células paratireoidianas;

2) sintese de PTH, deflagrada após várias horas de hipocalcemia persistente;

3) síntese de PTH, decorrente do crescimento do número de células paratireoidianas, após dias de hipocalcemia ${ }^{3,110}$. 


\subsubsection{Retenção de Fósforo}

Vários autores têm confirmado a importância do papel do fósforo na fisiopatogenia do HPT2 14,22,28,53,64,117,118. A hiperfosfatemia pode estimular a secreção de PTH, tanto de forma direta quanto indireta, via hipocalcemia. Os mecanismos pelos quais níveis elevados de fósforo sérico podem acarretar hipocalcemia são: aumento da resistência óssea ao PTH com conseqüente redução da liberação do cálcio ósseo; diminuição da síntese de calcitriol, por inibição da 1a-hidroxilase, diminuindo assim a absorção intestinal de cálcio; e, por fim, interação físico-química com o cálcio plasmático ${ }^{37,44,98}$.

O fósforo sérico parece exercer uma ação direta e independente sobre as glândulas paratireóides, estimulando a produção de PTH, através de sua ação em uma proteína de membrana das células paratireoidianas, descrita por Tatsumi et al. ${ }^{122}$, denominada de co-transportador $\mathrm{Na} / \mathrm{Pi}$. Nesse mesmo sentido, Silver et al. ${ }^{113}$ demonstraram que, independentemente do cálcio e da vitamina $D$, o fósforo pode ser responsável direto pelo desenvolvimento do HPT2. Estes autores observaram que ratos mantidos com níveis normais de cálcio e vitamina $D$, quando alimentados com dieta rica em fósforo, apresentavam hiperplasia das células paratireóides; em contrapartida, ratos sob as mesmas condições, porém alimentados com dieta pobre em fósforo, praticamente não apresentavam proliferação celular das glândulas paratireóides.

\subsubsection{Diminuição dos Níveis Séricos de Calcitriol}

Com a progressão da IRC, e conseqüente redução da massa renal, ocorre diminuição da secreção de calcitriol, principalmente com a queda do ritmo de filtração glomerular (RFG) abaixo de $50 \mathrm{~mL} / \mathrm{min}^{116}$. Este fato leva à diminuição da absorção intestinal de cálcio e, conseqüentemente, a hipocalcemia. Além disso, o calcitriol diminui a inibição sobre a secreção de PTH devido à redução do 
número de seus receptores nas glândulas paratireóides, especialmente naquelas que apresentam hiperplasia nodular ${ }^{45,46,114,116 .}$

\subsubsection{Resistência Esquelética à Ação Calcêmica do PTH}

Nos pacientes com IRC, a resistência esquelética à ação calcêmica do PTH implica em menor incremento do cálcio sérico frente a elevações do PTH, resultando, desta forma, em hipocalcemia 114,116. Alguns fatores podem estar envolvidos nesta resistência. Entre eles, destaca-se a hiperfosfatemia, as toxinas urêmicas, os distúrbios da vitamina $\mathrm{D}$ e a hiporregulação dos receptores de PTH. Dessa forma, para manter uma remodelação óssea normal são necessários niveis mais elevados de PTH, em torno de 2 a 4 vezes o limite superior de referência para indivíduos normais ${ }^{41,72}$.

\subsection{Tratamento do HPT2}

As medidas terapêuticas para a prevenção e controle do HPT2 devem ser precoces, já na fase pré-dialítica. O tratamento do HPT2 compreende medidas clínicas e cirúrgicas, incluindo a adequação na ingestão de proteína, cálcio e fósforo dietético.

\subsubsection{Tratamento Clínico do HPT2}

O tratamento clínico do HPT2 inclui o controle da hiperfosfatemia e do aumento do PTH, a correção da hipocalcemia e o uso de calcitriol ou de seus análogos $^{33,115}$.

O controle da hiperfosfatemia envolve várias medidas: orientação dietética, intensificação da diálise e uso de quelantes de fósforo ${ }^{34,36,73}$. A etapa inicial do controle da hiperfosfatemia consiste na restrição da ingestão de fósforo. 
Este objetivo é, por vezes, difícil de ser alcançado em virtude da importante restrição alimentar a qual os pacientes são submetidos, necessitando que os mesmos estejam bem esclarecidos e motivados para que aderência satisfatória seja obtida. Além disso, existe o risco do paciente desenvolver desnutrição em casos extremos de restrição protéica.

A distribuição multicompartimental do fósforo no organismo dificulta sua eliminação através de métodos dialíticos. Enquanto a ingestão diária de fósforo é cerca de $1500 \mathrm{mg}$, a eliminação pela hemodiálise é de $800 \mathrm{mg} / \mathrm{sessão} \mathrm{e} \mathrm{no} \mathrm{CAPD}$ é de $300 \mathrm{mg} / \mathrm{dia}$. Desta forma, pode ocorrer permanente tendência a um balanço positivo de fósforo ${ }^{79,109}$. Objetivando aumentar a eficácia da eliminação de fósforo pela hemodiálise, pode-se aumentar a superfície do dialisador, prolongar o tempo de diálise por sessão e aumentar o número sessões semanais ${ }^{73}$. Entretanto, estas medidas nem sempre são possiveis para os pacientes, pois envolvem efeitos secundários como mal estar, hipotensão, câimbras, etc., além da dificuldade em permanecer maior tempo nas unidades de diálise.

Com freqüência, faz-se necessário também o uso de quelantes de fósforo. Os sais de cálcio (carbonato de cálcio e acetato de cálcio) são os compostos mais utilizados, podendo, além de controlar o fósforo, ser utilizados como suplementos na correção da hipocalcemia. Quelantes a base de alumínio já foram muito utilizados no passado, porém estes compostos, apesar de terem eficácia superior aos sais de cálcio ${ }^{34,36,73}$, apresentam o risco da intoxicação alumínica, devendo portanto serem utilizados em situações extremas e por curto periodo de tempo. Recentemente, tem sido utilizado o Sevelamer, um novo quelante sem cálcio ou alumínio. Este tem a vantagem de não oferecer risco de intoxicação alumínica e sobrecarga de cálcio ao paciente ${ }^{34,36,73}$, porém existem poucos estudos sobre sobrevida e qualidade de vida nos pacientes em uso deste quelante, além disto o custo desta medicação é muito elevado, fator este que dificulta ainda mais sua ampla utilização ${ }^{79,109}$. Por outro lado, Chertow et al ${ }^{18} \mathrm{em}$ 2002, conduziram um estudo clínico randomizado comparando o sevelamer com um quelante de fósforo a base de cálcio em 200 pacientes em hemodiálises, e verificaram que os pacientes tratados com sevelamer ficaram hospitalizados em 
média 567 dias comparando com 980 dias para os pacientes tratados com sais de cálcio, representando um menor custo com hospitalização.

O uso de derivados de vitamina $\mathrm{D}$ diminui a secreção de PTH, indiretamente por aumentar a absorção intestinal de cálcio, evitando a hipocalcemia, e diretamente por atuar nos receptores de vitamina $D$ na paratireóide ${ }^{30,55}$. Em pacientes com o produto cálcio $\times$ fósforo $(\mathrm{Ca} \times \mathrm{P})$ controlado e altos níveis de PTH, o uso de calcitriol está indicado. Porém, esse tratamento deve ser realizado com cautela, pois um dos efeitos indesejáveis e limitantes deste tratamento é o agravamento da hiperfosfatemia el ou hipercalcemia acentuada $^{108}$.

\subsubsection{Tratamento Cirúrgico do HPT2}

A paratireoidectomia ou PTX é o tratamento cirúrgico que implica na retirada total ou parcial das glândulas paratireóides. Um registro de paratireoidectomias realizado na região de Lombardia (Itália), com 14.800 pacientes em diálise, mostrou que após 10-15 anos de tratamento, 9,2\% dos pacientes foram submetidos a PTX, e com o aumento do tempo em diálise para $15-20$ anos, $20,8 \%$ dos pacientes realizaram $\mathrm{PTX}^{29,78}$.

A indicação de PTX é centrada na falta de resposta ao tratamento clínico e na severidade do HPT2. São considerados índices de severidade: níveis de PTH sérico na forma intacta (iPTH) acima de $500 \mathrm{pg} / \mathrm{mL}$, detecção de glândulas paratireóides muito aumentadas através de métodos de diagnóstico por imagem, hipercalcemia, hiperfosfatemia, sintomas colaterais severos (dor articular e óssea, prurido, irritabilidade, fraqueza muscular, etc), deformidades esqueléticas, calcificações ectópicas, perda óssea, calcifilaxia e anemia resistente à eritropoetina ${ }^{123,124}$.

O pós-operatório da PTX é, freqüentemente, marcado pela presença de hipocalcemia e hipofosfatemia. Isto se explica pela diminuição da remodelação óssea após a normalização dos níveis de PTH. Em geral, este processo leva a uma maior mineralização óssea, necessitando de quantidades consideráveis de 
cálcio e fósforo, caracterizando a chamada "fome óssea" 54,89,108,121. Neste período a oferta dietética destes nutrientes deve ser suficiente para a prevenção da diminuição acentuada do Ca e $P$ séricos ${ }^{68}$.

A condição nutricional pós PTX pode ser melhorada, pois nota-se aumento dos níveis séricos de albumina e proteína total, do hematócrito e do peso seco do indivíduo. Além disso, com a redução da dor osteoarticular, pode ocorrer aumento da atividade física diária, o que pode acarretar em aumento do apetite ${ }^{63,133}$. Outro importante benefício observado com a realização da PTX, é a melhora da resposta inflamatória, com aumento dos níveis séricos de $\lg G, \operatorname{lgA}$ e $\lg { }^{133}$.

Mais recentemente, novas modalidades terapêuticas, como a injeção de etanol e calcitriol diretamente em glândulas paratireóides, foram relatadas como uma opção a PTX. Porém, até o momento, há controvérsias sobre os benefícios destes novos tratamentos e se eles podem ser considerados como alternativas a PTX ${ }^{50}$.

\subsection{Nutrição na IRC e no HPT2}

Nos anos recentes percebe-se um crescente interesse no que diz respeito às desordens nutricionais e à terapia nutricional para pacientes com doenças renais. Com o objetivo de retardar a progressão da doença, adequar o estado nutricional, precaver desordens no metabolismo de minerais $e$ conseqüentemente melhorar a qualidade de vida destes pacientes, diversos estudos $1,88,105,135$ têm procurado elucidar os mecanismos responsáveis pelas alterações metabólicas e nutricionais apresentadas, como: acidose metabólica, deficiências de vitaminas e minerais, aumento da peroxidação lipídica, diabetes, problemas ósseos, hipotensão e anemia.

A desnutrição energético-protéica é muito freqüente em pacientes com IRC. Estima-se que a desnutrição esteja presente em $40 \%$ dos pacientes com IRC em hemodiálise ${ }^{8,26}$. Entre as múltiplas causas destacam-se a anorexia, ingestão deficiente de nutrientes, perda de nutrientes e catabolismo durante os processos dialíticos, distúrbios hormonais (como o aumento do PTH) e do equilíbrio ácido- 
básico, intolerância a glicose, inflamação crônica, tempo prolongado em hemodiálise, etc. A desnutrição nestes pacientes pode piorar a evolução clínica, pois favorece quadros infecciosos, dificulta a reabilitação do paciente e piora sua qualidade de vida ${ }^{1,88,135}$.

Um importante agravante ao deterioramento do estado nutricional nestes pacientes são niveis constantemente elevados de PTH. Este aporte contínuo de PTH pode exercer uma ação tóxica sobre o metabolismo energético e principalmente protéico, promovendo catabolismo protéico, perda de peso, fraqueza e atrofia muscular, e balanço nitrogenado negativo ${ }^{104}$. Tais modificações podem levar a alterações no metabolismo muscular, inibindo a produção, transporte e utilização de energia ${ }^{6,86}$.

Nos últimos anos, muita atenção tem sido dada a uma síndrome conhecida como DIA (Desnutrição - Inflamação e Aterosclerose), muito freqüente nos pacientes em diálise. Níveis elevados de citocinas inflamatórias, como IL-6, TNF- $\alpha$ e proteínas-reativas de fase aguda (como a proteína C-reativa) são freqüentemente encontrados nestes pacientes. Os efeitos negativos dos níveis elevados destes marcadores de inflamação estão relacionados à desnutrição através de efeitos negativos na síntese protéica e na taxa de catabolismo fracional da albumina ${ }^{62}$. O estado inflamatório também está relacionado a alterações na secreção de hormônios, como leptina, insulina e adiponectina, alterações na composição de proteínas plasmáticas e na estrutura e função endotelial que, em conseqüência, promovem desenvolvimento de doença vascular ${ }^{134}$.

Para evitar a desnutrição nestes pacientes, orientação nutricional adequada tem sido recomendada. O National Kidney Foundation - Disease Outcome Quality Initiatives (K/DOQI) de $2003^{2,92}$, para indivíduos clinicamente estáveis em HD e com doença óssea, recomenda que a ingestão de energia proveniente da dieta seja de $35 \mathrm{Kcal} / \mathrm{Kg} / \mathrm{dia}$, para manutenção de peso e balanço nitrogenado neutro, dependendo da atividade e da composição corporal. A ingestão de proteína deve ser no mínimo $1,2 \mathrm{~g} / \mathrm{Kg} / \mathrm{dia}$, das quais 50 a $80 \%$ de alto valor biológico (AVB), com o objetivo de assegurar uma ingestão adequada de aminoácidos essenciais. 
Com relação à ingestão de micronutrientes, com a deficiência e a resistência à ação da forma ativa da vitamina $D$ na absorção intestinal e na elevação da reabsorção óssea de cálcio, os requerimentos deste mineral aumentam nos pacientes com IRC e HPT2. Recomenda-se então, que a ingestão de cálcio alcance os níveis propostos pelas DRI's ( $\mathrm{Al}$ - ingestão adequada) diária para adultos (1000 a $1500 \mathrm{mg} / \mathrm{dia})^{92}$, sendo $500 \mathrm{mg} /$ dia proveniente da dieta, e 500 a $1000 \mathrm{mg} /$ dia proveniente dos quelantes de fósforo a base de cálcio, a fim de evitar calcificação vascular. Caso o paciente não faça uso de quelante a base de cálcio, a recomendação de cálcio dietético será em torno de $1220 \mathrm{mg} /$ dia. Por outro lado, o fósforo deve ser restringido em pacientes com níveis séricos de fósforo acima de $5,5 \mathrm{mg} / \mathrm{dl}$, devendo ser ingerido aproximadamente $700 \mathrm{mg} / \mathrm{dia}$, ou quantidade inferior a $17 \mathrm{mg} / \mathrm{kg} / \mathrm{dia}^{23,80,92}$.

Como a HD pode não remover a carga ingerida de fósforo alimentar suficientemente, a dieta assume importante papel no controle dos níveis séricos de fósforo, com indicação de restrição de produtos lácteos, chocolate, sementes oleaginosas, leguminosas, alguns refrigerantes (colas escuras), carnes, ovos, etc. Por outro lado, pacientes em HD necessitam de ingestão rica em proteínas, que concomitantemente é elevada em fósforo. Assim, a orientação nutricional com relação à substituição de alimentos, porções adequadas, e mesmo correta utilização de quelantes, é fundamental na prevenção da desnutrição e adequação do metabolismo mineral ${ }^{23,80}$.

\subsection{Avaliação Nutricional de Pacientes com IRC e HPT2}

A monitoração periódica do estado nutricional na insuficiência renal parece capaz de frear a evolução da enfermidade em suas etapas iniciais e retardar o aparecimento de complicações urêmicas em estágios avançados ${ }^{96}$.

Uma avaliação nutricional adequada é de fundamental importância para a instituição de terapia nutricional que contribua para a melhora da qualidade de vida destes pacientes ${ }^{88}$. A avaliação nutricional deve detectar desde a deficiência subclínica de nutrientes até a desnutrição grave. Não existe uma única 
determinação que possa atingir todos esses objetivos. Em função disto, muitos índices, cada um representando uma categoria específica, são utilizados de maneira independente e, depois, avaliados em conjunto para avaliar o estado nutricional do paciente renal ${ }^{105}$.

Para a avaliação nutricional de pacientes com IRC, devem ser utilizados métodos subjetivos, como a avaliação global subjetiva, análise da ingestão alimentar, e/ou métodos objetivos, como a antropometria (peso, altura, circunferência do braço, pregas cutâneas, índice de massa corporal, bioimpedância elétrica, densitometria óssea, etc.) e as medidas bioquímicas (albumina, transferrina, uréia sérica, creatinina, etc.) ${ }^{21,68,105,135}$.

A antropometria é considerada um importante instrumento, tanto para a avaliação do estado nutricional como para o monitoramento de mudanças conseqüentes a intervenção dietética ${ }^{88}$.

Rezende et al. ${ }^{104}$, comparando o estado nutricional de pacientes em HD com e sem HPT2, verificaram que mesmo ambos os grupos apresentando semelhante ingestão energética e protéica (mesmo que insuficiente), houve correlação positiva entre o PTH e a taxa de catabolismo protéico no grupo com HPT2. Peters et al. ${ }^{99}$, avaliando o estado nutricional de pacientes em HD com HPT2 leve e severo, observaram que mesmo os dois grupos apresentando semelhante e adequada ingestão alimentar, o grupo com HPT2 severo apresentava parâmetros antropométricos estatisticamente menores que o grupo com HPT2 leve. Cuppari et al ${ }^{24}$ comparando pacientes em HD com leve a moderado HPT2 e severo HPT2, apesar de não terem verificado a ingestão alimentar dos pacientes presentes no estudo, verificaram que o gasto energético (medido por calorimetria indireta) foi maior e que a circunferência muscular do braço foi menor nos pacientes com severo HPT2.

Estudos comprovam ${ }^{1,39}$ que a somatória das pregas cutâneas, método utilizado para a avaliação da composição corporal de indivíduos e grupos populacionais, apesar de ser uma técnica simples, não invasiva e de baixo custo, pode ser propensa à falta de precisão em pacientes renais, devido a alterações na 
hidratação com conseqüente turgor da pele (edema), presença de fístula arteriovenosa que prejudica a obtenção das medidas, etc.

$A$ impedância bioelétrica $(B \mid A)$ é um método que tem sido utilizado para estimar a composição corporal de pacientes renais. Trata-se de um método simples, não invasivo, de fácil manejo, que requer pouco tempo, e não causa desconforto ao paciente ${ }^{43,75,83,95}$.

A análise da BIA baseia-se na medida da resistência total do corpo à passagem de uma corrente elétrica de baixa amplitude (800 mA) e de alto freqüência $(50 \mathrm{KHz})$, mensurando propriedades como a Impedância $(Z)$, Resistência (R), Reactância (Xc) e Ângulo de Fase $(\phi)^{43,75,83,95}$.

A passagem da corrente elétrica por um condutor vai depender do volume do condutor (o corpo), o comprimento do condutor (altura) e sua impedância, que reflete a resistência à passagem de uma corrente elétrica. Portanto a impedância $(Z)$ é diretamente proporcional ao diâmetro do condutor $43,75,83,95$.

A corrente elétrica flui através do corpo pela movimentação dos íons. Quando esta corrente é aplicada a um corpo humano há sempre uma oposição ao fluxo, resistência $(R)$, que é inversamente relacionada à condutividade ou condutância. No corpo humano, os tecidos magros (sem gordura) são altamente condutores, por conterem grande quantidade de água e eletrólitos e representam um meio de baixa resistência elétrica. Já gordura e ossos, são maus condutores ou meios de alta resistência, com pouca quantidade de água ou eletrólitos condutores. Portanto, a $\mathrm{R}$ é inversamente proporcional à quantidade de fluidos $43,75,83,95$

A reactância $(X c)$, também conhecida como resistência capacitiva, é a oposição ao fluxo da corrente elétrica causada pela capacitância. Por definição um capacitor consiste de duas ou mais placas condutoras separadas por um isolante ou material não condutivo, utilizado para armazenar carga elétrica. No corpo humano, a membrana celular é formada por uma camada de lipídios não condutora entre duas camadas condutoras de proteínas. Teoricamente a Xc é a 
medida da capacitância da membrana celular e o indicador da quantidade da massa intracelular ou da massa celular corpórea (massa magra) $43,75,83,95$.

O ângulo entre $\mathrm{R}$ e Xc é denominado ângulo de fase $(\phi)$, é um método linear de medir a relação entre resistência e reactância em circuitos elétricos em série ou paralelos. $\phi$ pode variar de 0 a 90 graus; 0 grau se o circuito é só resistivo (como em um sistema sem membranas celulares) e 90 graus se o circuito é só capacitivo (só membranas, sem fluidos). Um $\phi$ de 45 graus reflete um circuito (ou corpo) com igual quantidade de $\mathrm{Xc}$ e $\mathrm{R}$, como em vegetais frescos. A média do $\phi$ para um indivíduo saudável é aproximadamente de 4 a 10 graus, dependendo do sexo. $\phi$ menores (baixa $X c$ ) podem ser associados à morte celular ou a uma alteração na permeabilidade seletiva da membrana celular. $\phi$ mais altos (Xc alta) podem ser associados a maiores quantidades de membranas celulares intactas, isto é, maior massa celular corpórea ${ }^{43,75,83,95}$.

Baseado na análise das propriedades da $\operatorname{BIA}\left(R, X_{c}\right.$ e $\left.\phi\right)$, o método permite estimar de forma válida e precisa componentes corporais como a massa magra (MM), a gordura corporal total (GCT), a água corporal total (ACT) e a massa celular $(M C)$ do organismo, através de equações de regressão múltipla da $\mathrm{BIA}$, que incluem geralmente estatura, peso, idade e sexo ${ }^{100}$.

Apesar deste método sofrer influência da distribuição anormal de água entre os compartimentos intra e extra celular que ocorre nos pacientes renais crônicos, vários estudos comprovam que a BIA é um método válido e confiável para a avaliação da composição corporal destes pacientes ${ }^{17,20,39,61,88}$. Entretanto, tem sido sugerida a análise da BIA vetorial (BIVA, Bioeletrical Impedance Vector Analysis) para pacientes em HD. Este método de análise vetorial, denominado Gráfico Resistência-Reactância (Gráfico Xc/R) confronta o vetor medido de um indivíduo com o intervalo de referência de uma população normal, de forma elipsoidal (com elipses de tolerância de 50\%, 75\% e 95\%), expressado em percentis da distribuição normal bivariada. Uma propriedade importante deste método é de se trabalhar independentemente do conhecimento do peso corporal. Utilizando o Z-escore de $\mathrm{R}$ e Xc se constrói um gráfico RXc-escore para a interpretação dos vetores medidos ${ }^{100}$. 
Considerando que níveis elevados de PTH implicam em conseqüências adversas no estado nutricional de pacientes renais crônicos, este estudo irá avaliar os efeitos da diminuição dos níveis deste hormônio, através da PTX, na composição corporal de pacientes com HPT2 seis meses após a cirurgia. 
Objetivos 


\section{OBJETIVOS}

\subsection{Objetivo Geral}

Avaliar a evolução do estado nutricional de pacientes com insuficiência renal crônica e hiperparatireoidismo secundário após a realização da paratireoidectomia

\subsection{Objetivos Específicos}

- Avaliar alterações na ingestão de macro e micronutrientes em pacientes com IRC e HPT2 após a paratireoidectomia;

- Investigar alterações na composição corporal em pacientes com IRC e HPT2 após a paratireoidectomia;

- Avaliar possíveis alterações nos marcadores bioquímicos do estado nutricional, do estado inflamatório e de formação óssea após a paratireoidectomia;

- Investigar os efeitos do paratormônio na ingestão alimentar, na composição corporal e nos marcadores bioquímicos do estado nutricional, estado inflamatório e metabolismo ósseo. 


\section{Casuistica e Métodos}




\section{CASUÍSTICA E MÉTODOS}

O presente estudo foi realizado no período de março de 2002 a abril de 2004, no Ambulatório de Osteodistrofia Renal da disciplina de Nefrologia da Faculdade de Medicina da Universidade de São Paulo, situado no Instituto Central do Hospital das Clínicas (ICHC-FMUSP). Neste ambulatório são atendidos pacientes de diversas unidades de diálise da cidade de São Paulo e seus arredores.

Os pacientes são encaminhados a este ambulatório devido a sua excelência no tratamento da Osteodistrofia Renal. Na consulta inicial são solicitados exames laboratoriais e radiológicos para avaliação e caracterização da doença. Antes dos pacientes serem encaminhados à PTX, é realizada a biopsia óssea para que através do estudo histomorfométrico, os pacientes sejam classificados quanto ao tipo da doença óssea.

Durante o período deste estudo, A PTX era realizada em apenas 01 paciente ao mês. Todos os outros pacientes, permaneciam em tratamento clínico e nutricional, aguardando a realização da cirurgia.

\subsection{Pacientes}

Foram selecionados 24 pacientes adultos, de ambos os sexos, com IRC e HPT2, todos em programa de hemodiálise, que durante o período de estudo, estavam aguardando a realização da PTX, e não apresentavam nenhum dos critérios de exclusão (pacientes com doenças concomitantes), como:

- infeç̧ões recentes (<3meses);

- tuberculose (TB) em tratamento;

- doença intestinal;

- alcoolismo crônico;

- síndrome da imunodeficiência adquirida (HIV);

- doenças malignas;

- insuficiência cardíaca e pulmonar grave; 
- insucessos de transplante renal nos últimos 6 meses;

- pacientes em uso de mineralocorticóides e anabolizantes como 17decanoato de nandrolona.

Destes 24, 03 pacientes faleceram, 04 realizaram transplante renal durante o estudo, 02 pacientes tiveram a PTX suspensa devido a alterações cardiológicas que impossibilitaram o ato cirúrgico, e 03 pacientes continuaram apresentando hiperparatireoidismo secundário após os 06 meses de cirurgia. Portanto, são de 12 pacientes, avaliados antes e 06 meses após a realização da PTX, os resultados apresentados neste trabalho.

Todos os pacientes foram esclarecidos quanto aos objetivos da pesquisa, antes que esta tivesse início, e o termo de consentimento (Anexo1), foi assinado quando estivessem de total acordo com o descrito neste.

\subsection{Protocolo de estudo}

A coleta dos dados foi realizada no próprio Ambulatório, nos dias que antecediam a cirurgia, e seis meses (+/- 02 semanas) após a realização desta. Os dados antropométricos e de ingestão alimentar foram coletados pelo próprio investigador, e os exames bioquímicos foram realizados no Laboratório Central do ICHC-FMUSP.

Todos os pacientes realizaram avaliação nutricional por meio da avaliação da ingestão alimentar, de medidas antropométricas e de medidas bioquímicas. Avaliação do metabolismo ósseo foi realizada por meio de medida bioquímica de formação óssea. Estas avaliações foram feitas nestes pacientes antes e 06 meses após a realização da PTX. 


\subsubsection{Avaliação da ingestão alimentar}

Para a avaliação da ingestão alimentar, foi utilizado o registro alimentar de 3 dias, no qual o próprio paciente ou o responsável anotaram em um formulário especialmente desenhado (Anexo 2), todos alimentos e bebidas consumidos ao longo de 03 dias, sendo 02 dias durante a semana (01 dia de hemodiálise e outro não), e 01 dia no final de semana.

O uso deste método de registro do consumo alimentar teve como objetivo avaliar a ingestão média de energia (Kcal), proteínas $(\mathrm{g})$, cálcio $(\mathrm{mg})$ e fósforo $(\mathrm{mg})$. Este método foi escolhido, pelo fato do registro alimentar de 03 dias refletir com maior confiabilidade a ingestão atual do paciente, e pela importância de se quantificar a ingestão de micronutrientes como o cálcio e o fósforo ${ }^{11,125}$.

Para calcular a ingestão dos macro e micronutrientes analisados, foi utilizado o software Sistema de apoio e Decisão em Nutrição - versão 2.5, do Departamento de Informática em Saúde - UNIFESP/EPM ${ }^{4}$.

\subsubsection{Medidas Antropométricas}

A avaliação antropométrica constou do peso relatado pelo paciente, mensuração da estatura e realização da impedância bioelétrica.

\section{- Peso e estatura}

Neste estudo foi utilizado o peso relatado pelo paciente, uma vez os pacientes atendidos no Ambulatório de Osteodistrofia Renal do ICHC realizam hemodiálise em diferentes centros de diálise da cidade de São Paulo e seus arredores, em dias diferentes do dia de atendimento ambulatorial. Assim, o peso relatado pelo paciente foi o peso mensurado logo após a última sessão de HD (considerado como peso seco), na unidade de diálise o qual faz parte.

A medida da estatura foi realizada no ambulatório, utilizando-se uma barra metálica com escala em $\mathrm{cm}$, acoplada a uma balança digital tipo plataforma, da marca Filizola. O paciente foi orientado a tirar os sapatos, 
permanecer de costas para o marcador, em posição ereta, com os pés unidos e com a posição da cabeça voltada para frente com o olhar na linha do horizonte. A leitura da estatura foi feita no centímetro mais próximo, com variação de $0,5 \mathrm{~cm}$, quando a haste da barra vertical encostava-se à cabeça.

A partir das medidas de peso e estatura obtidas, calculou-se o índice de massa corporal (IMC), que relaciona o peso do indivíduo dividido pelo quadrado da altura, em metros ${ }^{42}$, ou seja:

$$
\mathrm{IMC}=\text { Peso }(\mathrm{Kg}) / \text { Altura }\left(\mathrm{m}^{2}\right)
$$

Os pacientes foram classificados como baixo peso, eutróficos, com sobrepeso, ou obesos de acordo com a classificação da OMS ${ }^{132}$, ou seja:

$\begin{array}{ll}\text { IMC }\left(\mathbf{K g} / \mathbf{m}^{2}\right) & \text { Classificação } \\ <18,5 & \text { baixo peso } \\ 18,5-24,9 & \text { eutrófico } \\ 25,0-29,9 & \text { sobrepeso } \\ 30,0-34,9 & \text { obesidade grau I } \\ 35,0-39,9 & \text { obesidade grau II } \\ \geq 40 & \text { obesidade grau III }\end{array}$

\section{- Impedância bioelétrica}

Para a realização da impedância bioelétrica, foi utilizado um aparelho Quantum BIA - 101Q da marca RJL-101 (Detroit, MI), tetrapolar, com apresentação digital dos valores de resistência $(R)$ e reactância $(X c)$.

As medidas de impedância bioelétrica foram tomadas do lado direito do paciente, que foi orientado a manter-se deitado em posição supina, com os braços abertos em ângulo de $30^{\circ} \mathrm{em}$ relação ao seu corpo. As pernas não tinham contato entre si. Calçados e meias foram retirados, e durante o teste o examinado não fez movimentos. 
O aparelho consta de um cabo preto e outro vermelho, sendo que cada cabo apresenta duas pinças de conexão, uma de cor vermelha e outra de cor preta. Os cabos pretos foram conectados nos eletrodos do pé, e os cabos vermelhos nos eletrodos da mão. As pinças de conexão de cor preta foram conectadas nos eletrodos distais, isto é, sobre o dedo médio da mão e acima dos nós dos dedos do pé, e as pinças de cor vermelha foram conectadas nos eletrodos proximais, isto é, na linha imaginária que divide a cabeça da ulna e se inicia na protuberância óssea do punho e na linha imaginária que divide os maléolos medial e lateral (Figura 1). Após a colocação dos cabos, o analisador é ligado e os valores de R e Xc são registrados.

Figura 1- Esquema representativo da colocação dos eletrodos distal e proximal, para a realização da impedância bioelétrica.

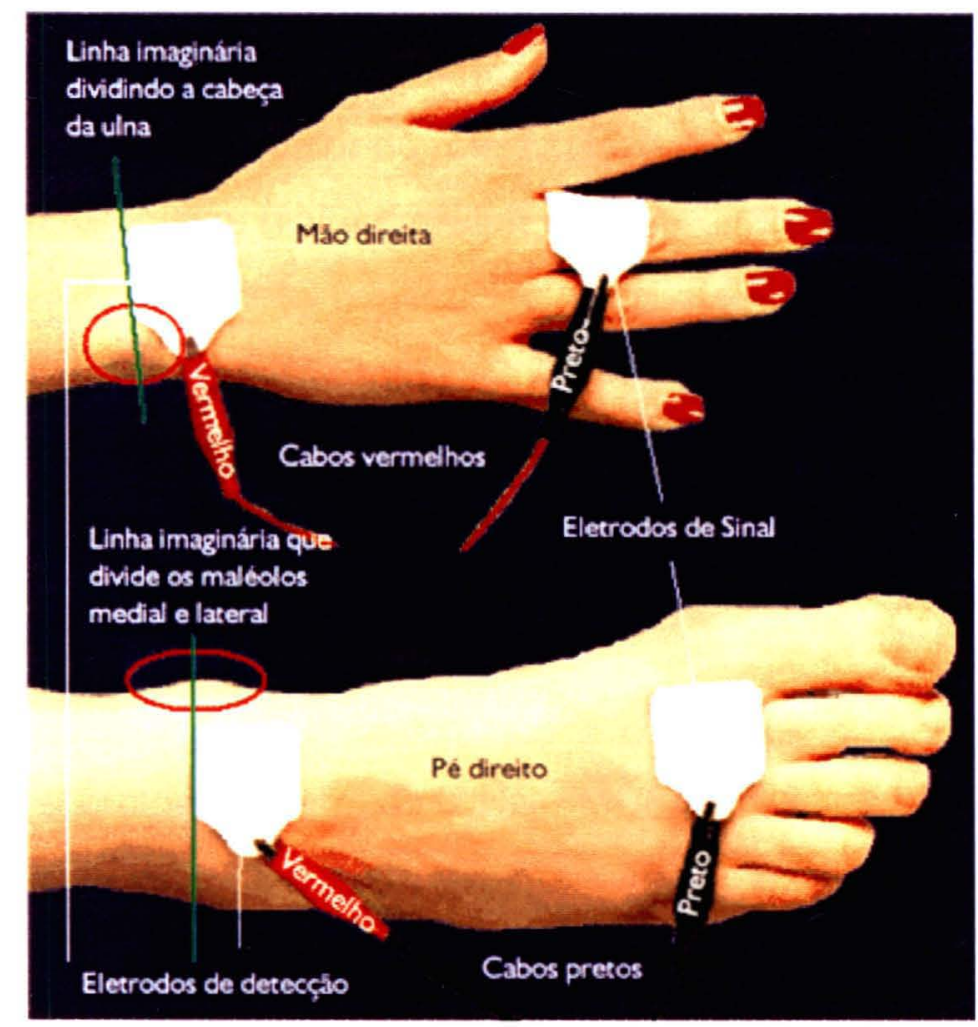

Adaptado: Colocação dos eletrodos proximal e distal, RJL SISTEMS - 101 
Utilizando o software RJL systems Cyprus 1.2 C Body Composition Analysis ${ }^{106}$, quando se aplica os valores de $\mathrm{R}, \mathrm{Xc}$, peso corporal, altura, sexo e idade do examinado, os valores do ângulo de fase, e dos componentes corporais como a gordura corporal total (GCT), massa magra (MM), água corporal total (ACT), água intracelular (AIC) e da água extracelular (AEC) nos são apresentados. Com os valores dos componentes corporais, foi realizada uma análise convencional da BIA.

Já com os valores das propriedades da BIA ( $R$ e Xc, divididos pela altura $(\mathrm{H})$ do paciente), foi feita uma análise vetorial da BIA com a ajuda do BIVA software ${ }^{101}$.

\subsubsection{Medidas Bioquímicas}

Os exames bioquímicos, realizados através da coleta do sangue dos pacientes, foram feitos no Laboratório Central do ICHC-FMUSP, pelo aparelho Auto Analyser Covas-Integra (Roche), os exames realizados foram:

- Albumina (valor de referência: 3,5 - 5,0 g/dl; método: nefelometria);

- Globulina (valor de referência: 2,5 - 3,0 g/dl; método: nefelometria);

- Proteína total (valor de referência: 6,0 - 8,0 g/dl; método: nefelometria);

- Proteina C reativa (valor de referência: $<5 \mathrm{mcg} / \mathrm{ml}$; método: nefelometria);

- Uréia (valor de referência: 10 - $45 \mathrm{mg} / \mathrm{dl}$; método: enzimático colorimétrico automatizado);

- Creatinina (valor de referência: 0,6 - 1,4 mg/dl; método: colorimétrico automatizado);

Vale ressaltar que a coleta de sangue também foi realizada no Laboratório Central do ICHC-FMUSP.

\subsubsection{Avaliação do metabolismo ósseo}

Para avaliação do metabolismo ósseo foram considerados os seguintes exames bioquímicos:

- Cálcio sérico (valor de referência: 8,5 - 10,5 mg/dL; método: colorimétrico automatizado); 
- Cálcio iônico (valor de referência: 4,64 - 5,28 mg/dL; método: eletrodo ín seletivo);

- Fósforo sérico (valor de referência: 2,3 - 4,6 mg/dL; método: colorimétrico automatizado);

- Fosfatase alcalina total (valor de referência: 40 - $190 \mathrm{U} / \mathrm{L}$; método: cinético automatizado);

- Fração óssea da fosfatase alcalina (valor de referência: até $20 \%$ da fosfatase alcalina total, isto é, até $38 \mathrm{U} / \mathrm{L} ;$ método: separação eletroforética);

- Paratormônio intacto (valor de referência: $10-65 \mathrm{pg} / \mathrm{ml}$; método: imunoradiométrico);

- $25(\mathrm{OH}) \mathrm{D}_{3}$ (valor de refência: $8,9-46,7 \mathrm{ng} / \mathrm{ml}$; método: radioimunoensaio).

Todos os métodos são recomendados pelos mais respeitados meios científicos internacionais.

\subsection{Análise Estatística}

Para a análise estatística foi utilizado o programa SPSS para Windows, versão 11.0 (SPSS, Inc., Chicago, IL, USA). Os resultados são apresentados em média \pm desvio padrão. As variações encontradas foram consideradas significativas se $p<0,05$. Para a verificação da normalidade das variáveis estudadas, utilizou-se o teste de Kolmogorov-Smirnov, sendo consideradas com distribuição normal quando $p>0,05$. Para estas variáveis foi aplicado o test $t$ de Student e o Coeficiente de Correlacão de Pearson.

\section{4 - Comitê de Ética}

Este trabalho teve aprovação do Comitê de Ética em Pesquisa (COEP) da Faculdade de Saúde Pública da Universidade de São Paulo FSP-USP. Protocolo de Pesquisa $n^{\circ} 824$ (Anexo 3). 


\section{Resultados}




\section{RESULTADOS}

\subsection{Características gerais}

As características gerais dos 12 pacientes estudados, encontram-se na Tabela 1. A média de idade foi de $43,4 \pm 12,7$ anos. $58,3 \%$ eram do sexo masculino e $41,7 \%$ do sexo feminino. O tempo em hemodiálise foi em média de $10,6 \pm 2,8$ anos (de 7 a 16 anos). As principais etiologias da IRC encontradas neste grupo foram a nefroesclerose $(33,3 \%)$ e a glomerulonefrite $(33,3 \%)$, seguidas da hipertensão arterial sistêmica $(16,7 \%)$ e da glomérulo esclerose $(16,7 \%)$. Nenhum dos pacientes apresentava diabetes mellitus.

\section{Tabela 1 - Características gerais dos pacientes estudados}

\begin{tabular}{cccccccc}
\hline ldade & \multicolumn{2}{c}{ Sexo } & Tempo em HD & \multicolumn{4}{c}{ Etiologia da IRC } \\
\cline { 2 - 5 } \cline { 5 - 7 } (anos) & $\boldsymbol{F}$ & $M$ & (anos) & NEC & GNF & HAS & GESF \\
\hline $43,4 \pm 12,7$ & $n=5$ & $n=7$ & $10,6 \pm 2,8$ & $n=4$ & $n=4$ & $n=2$ & $n=2$ \\
& $41,7 \%$ & $58,3 \%$ & & $33,3 \%$ & $33,3 \%$ & $16,7 \%$ & $16,7 \%$ \\
\hline
\end{tabular}

$\mathrm{F}=$ feminino; $\mathrm{M}=$ masculino; $\mathrm{HD}=$ hemodiálise; $\mathrm{IRC}=$ insuficiência renal crônica; NEC = nefroesclerose; GNF = glomerulonefrite; HAS = hipertensão arterial; GESF = glomerulo esclerose.

\subsection{Ingestão alimentar}

Comparando os dois momentos do estudo (pré e pós PTX) quanto à ingestão alimentar (Figura 2), apenas a ingestão de cálcio dietético apresentou diferença estatisticamente significante. Após a PTX, de 382,2 $\pm 209,6 \mathrm{mg}$ aumentou para $656,6 \pm 313,8 \mathrm{mg}(p<0,05)$. Houve tendência à elevação na ingestão de energia proveniente da dieta após a cirurgia, de 1667,0 $\pm 587,7$ Kcal 
para $279,7 \pm 87,9 \mathrm{~g}$; lipídeos: $55,6 \pm 27,3 \mathrm{~g}$ para $63,4 \pm 27,6 \mathrm{~g}$; proteínas: $65,4 \pm$ 21,3 g para 71,4 \pm 34,0 g; fósforo: $769,3 \pm 319,7 \mathrm{mg}$ para 963,2 \pm 408,7 mg; $p>0,05)$, como pode ser observado na figura 3 .

Figura 2 - Ingestão Ca e P dos pacientes com IRC e HPT2 antes e após a PTX

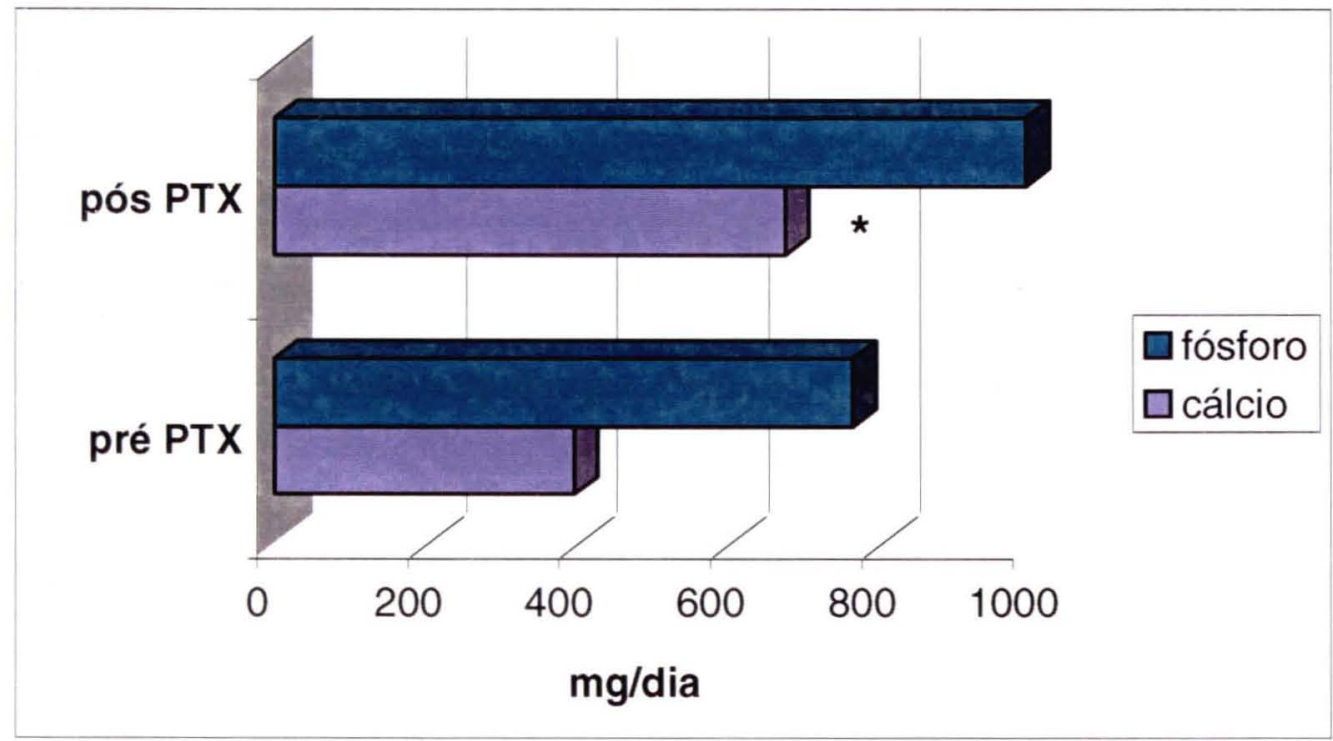

${ }^{*} \mathrm{p}<0,05$ vs. pré PTX

Figura 3 - Ingestão de macronutrientes de pacientes com IRC e HPT2 antes e após a PTX

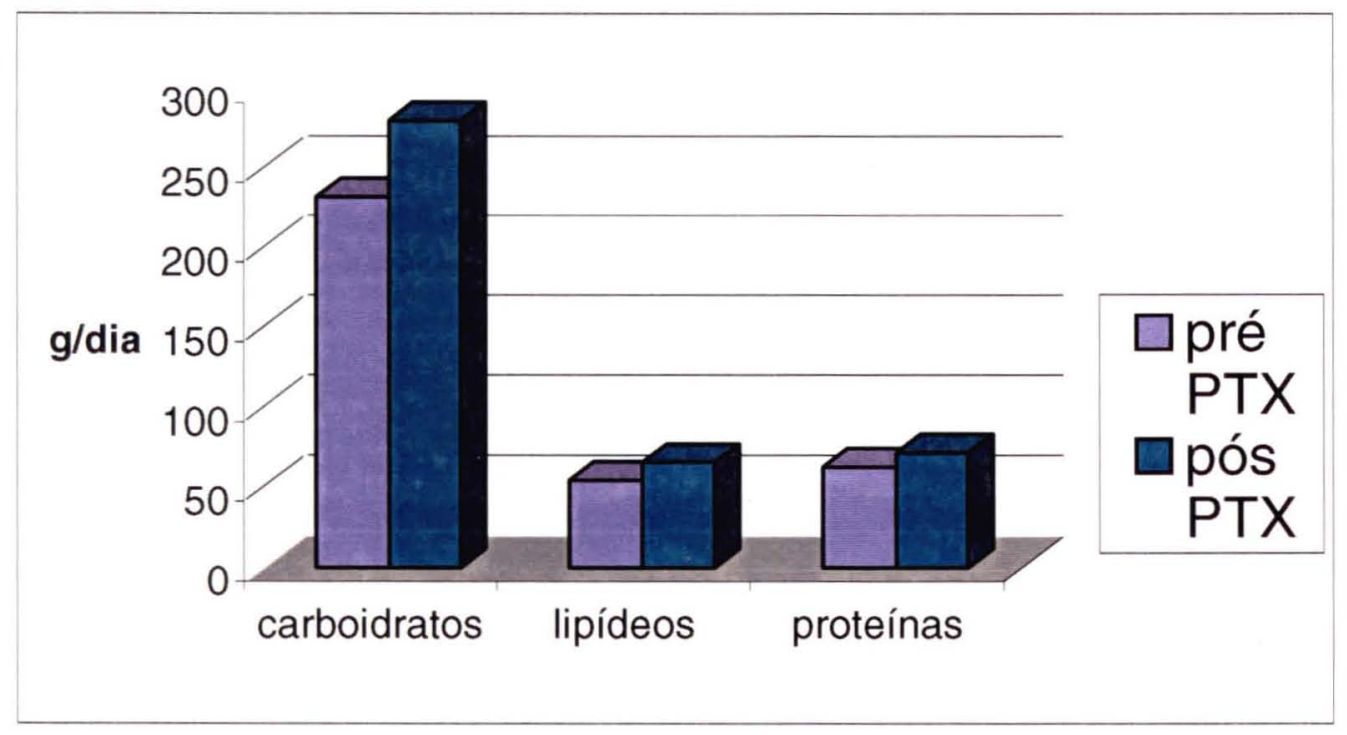


Com relação à adequação da ingestão alimentar, antes da PTX, observa-se inadequação quanto à ingestão de energia e de cálcio dietético. A ingestão de energia foi de $30,9 \pm 13,3 \mathrm{Kcal} / \mathrm{Kg} / \mathrm{dia}$, sendo que o recomendado é de $35 \mathrm{Kcal} / \mathrm{Kg} / \mathrm{dia}$, e a ingestão de cálcio dietético foi de $382,3 \pm 209,6 \mathrm{mg} / \mathrm{dia}$, porém a recomendação é de $500 \mathrm{mg} /$ dia. Os demais nutrientes atingiram as recomendações para pacientes em hemodiálise (K/DOQI, 2002).

Já após a PTX, como demonstrado anteriormente, houve melhora na ingestão de energia, as ingestões de proteína e de fósforo mantiveram-se adequadas. A ingestão de cálcio dietético, apesar de ter aumentado significantemente $(656,6 \pm 313,8 \mathrm{mg} / \mathrm{dia})$, ultrapassou o limite recomendado para pacientes em HD com doença óssea (500 mg/dia) caso o paciente faça uso de 1000 a $1500 \mathrm{mg}$ de sais de cálcio. Entretanto, como não há informações sobre o tipo e a quantidade de quelante de fósforo utilizado por esta amostra após a PTX, não se pode afirmar que a quantidade de cálcio dietético consumido após a PTX está inadequada.

Quanto à ingestão de fósforo, considerando que esta deve estar abaixo de $17 \mathrm{mg} / \mathrm{kg} / \mathrm{dia}$, no momento pré PTX todos apresentaram ingestão adequada $(13,6 \pm 6,0 \mathrm{mg} / \mathrm{Kg} / \mathrm{dia})$. No pós PTX, a ingestão média de fósforo aumentou para $17,4 \pm 6,8 \mathrm{mg} / \mathrm{Kg} / \mathrm{dia}$, porém esta não deve ser considerada inadequada, uma vez que os niveis séricos de $P$ estavam adequados (Tabela 6 ).

A porcentagem de adequação da ingestão alimentar em relação às recomendações do National Kidney Foundation - Disease Outcome Quality (K/DOQI) encontram-se na Figura 4. 
Figura 4 - Porcentagem de adequação da ingestão alimentar em relação às recomendações pelo K/DOQI.

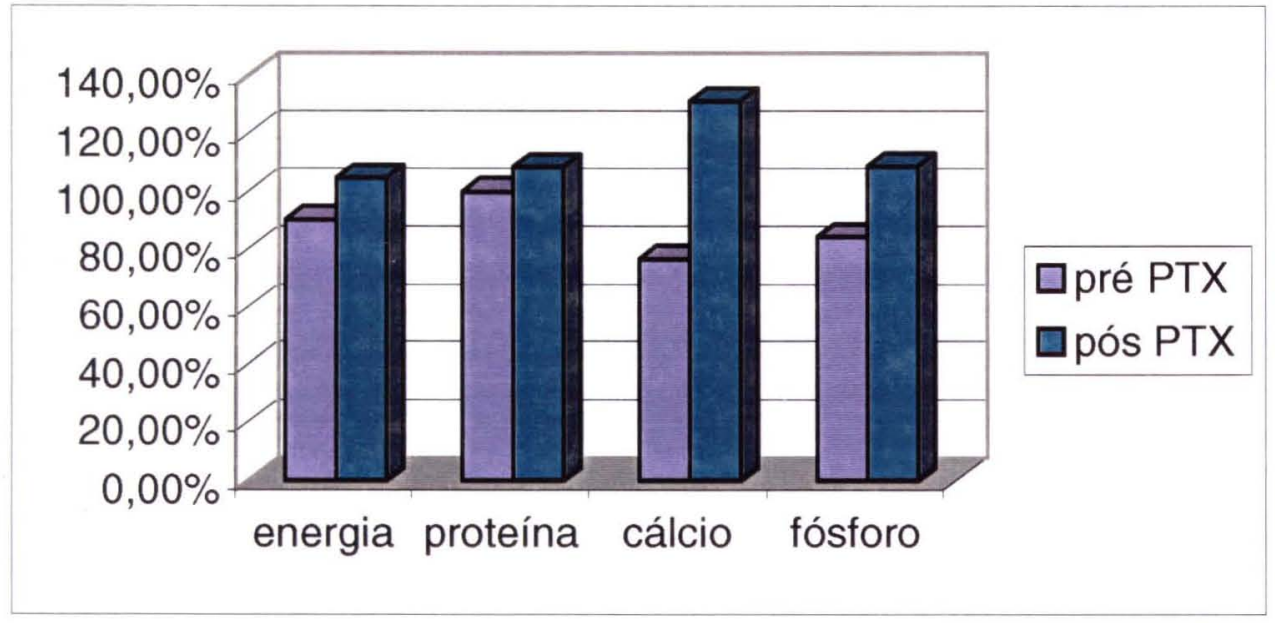

\subsection{Medidas antropométricas}

Em média, os valores do peso seco corporal $(\mathrm{Kg})$ e do índice de massa corporal (IMC), não tiveram alteração estatística significante após a cirurgia $(57,6$ $\pm 17,2 \mathrm{Kg}$ para $57,8 \pm 18,1 \mathrm{Kg}$ e $21,9 \pm 5,1 \mathrm{Kg} / \mathrm{m}^{2}$ para $21,9 \pm 5,5 \mathrm{Kg} / \mathrm{m}^{2}$, respectivamente). Pode-se notar, que a média do IMC da população estudada tanto antes como após a PTX, encontra-se perto do limite inferior para baixo peso, mesmo assim, ao classificar a amostra com o valor médio do IMC, os pacientes seriam eutróficos antes e após a cirurgia. A altura média dos pacientes é de 160,0 \pm 10 centímetros. Os valores médios de altura, peso seco e IMC estão na Tabela 2.

Tabela 2 - Valores médios de altura, peso seco e IMC dos pacientes estudados, antes e após a PTX

\begin{tabular}{lcc}
\hline & Pré PTX & Pós PTX \\
\hline Altura $(\mathbf{c m})$ & $160,0 \pm 10,0$ & $160 \pm 10,0$ \\
Peso seco $(\mathrm{Kg})$ & $55,7 \pm 16,4$ & $56,3 \pm 17,05$ \\
IMC $\left(\mathrm{Kg} / \mathrm{m}^{2}\right)$ & $21,5 \pm 4,7$ & $21,7 \pm 5,0$ \\
\hline
\end{tabular}


Avaliando ainda o IMC da amostra, na tabela 3 encontra-se o número de pacientes de acordo com as faixas de IMC, preconizadas pela Organização Mundial de Saúde (OMS, 1995), antes e após a PTX. A maioria dos pacientes foi considerada como eutrófico ou com sobrepeso, tanto antes como após a PTX. Pode-se notar, que antes da cirurgia, 04 pacientes foram considerados com baixo peso, e que após a cirurgia 02 deles apresentaram melhora.

Tabela 3 - Classificação dos pacientes antes e após PTX, segundo o IMC

\begin{tabular}{lcc}
\hline IMC & $\begin{array}{c}\text { Pré PTX } \\
n=12\end{array}$ & $\begin{array}{c}\text { Pós PTX } \\
\mathbf{n}=12\end{array}$ \\
\hline Baixo peso & $\mathrm{n}=4-33,3 \%$ & $n=2-16,7 \%$ \\
Eutrófico & $\mathrm{n}=6-50,0 \%$ & $n=6-50,0 \%$ \\
Sobrepeso & $n=1-8,3 \%$ & $n=2-16,7 \%$ \\
Obeso & $n=1-8,3 \%$ & $n=2-16,7 \%$ \\
\hline
\end{tabular}

Quanto às estimativas dos componentes corporais obtidos pela análise da impedância bioelétrica (Tabela 4), foi observado que a gordura corporal (GC) apresentou um aumento de $9,9 \pm 8,1 \mathrm{Kg}$ para $11,6 \pm 8,5 \mathrm{Kg}$, porém não foi estatisticamente significante. Não houve alteração na massa magra ( $M M)$, na água corporal total (ACT) e na água intra e extra celular (AIC e AEC) após a realização da PTX.

Tabela 4 - Estimativa dos componentes corporais dos pacientes em HD com HPT2, pela análise da impedância bioelétrica antes e após PTX

\begin{tabular}{lccc}
\hline & PRE PTX & PÓS PTX & P \\
\hline Gordura Corporal (Kg) & $9,9 \pm 8,1$ & $11,6 \pm 8,5$ & 0,116 \\
Massa Magra (Kg) & $47,2 \pm 12,8$ & $45,5 \pm 14,9$ & 0,310 \\
Água Extra Celular (I) & $15,2 \pm 3,5$ & $17,2 \pm 10,1$ & 0,468 \\
Água intra celular (I) & $18,5 \pm 6,5$ & $18,9 \pm 6,7$ & 0,086 \\
Água Corporal Total (I) & $33,7 \pm 8,9$ & $32,2 \pm 9,8$ & 0,395 \\
\hline
\end{tabular}


As propriedades da impedância bioelétrica, como resistência $(R)$, reactância $\left(X_{c}\right)$, e os valores do ângulo de fase $(\phi)$ obtidos antes e após a PTX (Tabela 5), apresentaram aumento após a PTX, porém apenas a Xc e $0 \phi$ apresentaram aumento estatisticamente significante $(44,1 \pm 15,6$ Ohms para 57,1 $\pm 14,4$ Ohms; $5,0 \pm 1,4$ graus para 5,6 $\pm 1,3$ graus; $p<0,05)$. O aumento da $X c$ pode ser explicado pela diminuição de massa magra e fluídos corporais. A R, apesar de seu aumento não ter sido estatisticamente significante, apresentou tendência à elevação, podendo isto ser atribuído ao aumento da gordura corporal. $O$ aumento do $\phi$ nestes pacientes, pode indicar melhora na doença de base.

Tabela 5 - Parâmetros vetoriais da impedância bioelétrica e valores do ângulo de fase antes e após a PTX

\begin{tabular}{lccc}
\hline & $\begin{array}{c}\text { PRE PTX } \\
\mathbf{n}=15\end{array}$ & $\begin{array}{c}\text { POS PTX } \\
\mathbf{N}=14\end{array}$ & $\mathbf{p}$ \\
\hline Resistência (Ohm) & $539,9 \pm 76,3$ & $612,1 \pm 117,2$ & 0,059 \\
Reactância (Ohm) & $44,1 \pm 15,6$ & $57,1 \pm 14,4^{*}$ & 0,020 \\
AF (graus) & $5,0 \pm 1,4$ & $5,6 \pm 1,3^{*}$ & 0,030 \\
Z R/H & $-0,3 \pm 1,5$ & $0,8 \pm 1,6^{*}$ & 0,049 \\
Z Xc/H & $-2,8 \pm 1,5$ & $-1,9 \pm 1,6$ & 0,096 \\
\hline
\end{tabular}

AF= ângulo de fase; $\mathrm{R}=$ resistência; $\mathrm{X}_{\mathrm{C}}=$ reactância; $\mathrm{H}=$ altura.

${ }^{\star} \mathrm{p}<0,05$ vs. pré PTX

Transformando os valores de $\mathrm{R}$ e Xc para valores de Z-escore (utilizando para este cálculo os valores médios de $\mathrm{R} / \mathrm{H}$ e $\mathrm{Xc} / \mathrm{H}$ da população mexicana-americana pareada por sexo, IMC e idade presente nos dados do NHANESIII ${ }^{61,94}$ ), tanto o Z-escore de R/H como o Z-escore de Xc/H apresentaram elevação de seus valores, entretanto, apenas o primeiro apresentou aumento estatisticamente significante (Tabela 5). Estes valores de Z-escore foram utilizados para a construção de gráfico RXc-escore com elipses de $95 \%, 75 \%$ e $50 \%$ de tolerância (Figura 5), para que a população estudada fosse avaliada clinicamente. 
Figura 5- Gráfico RXc-escore com elipses de 95\%, 75\% e 50\% de tolerância em pacientes com IRC e HPT2 antes e após PTX.

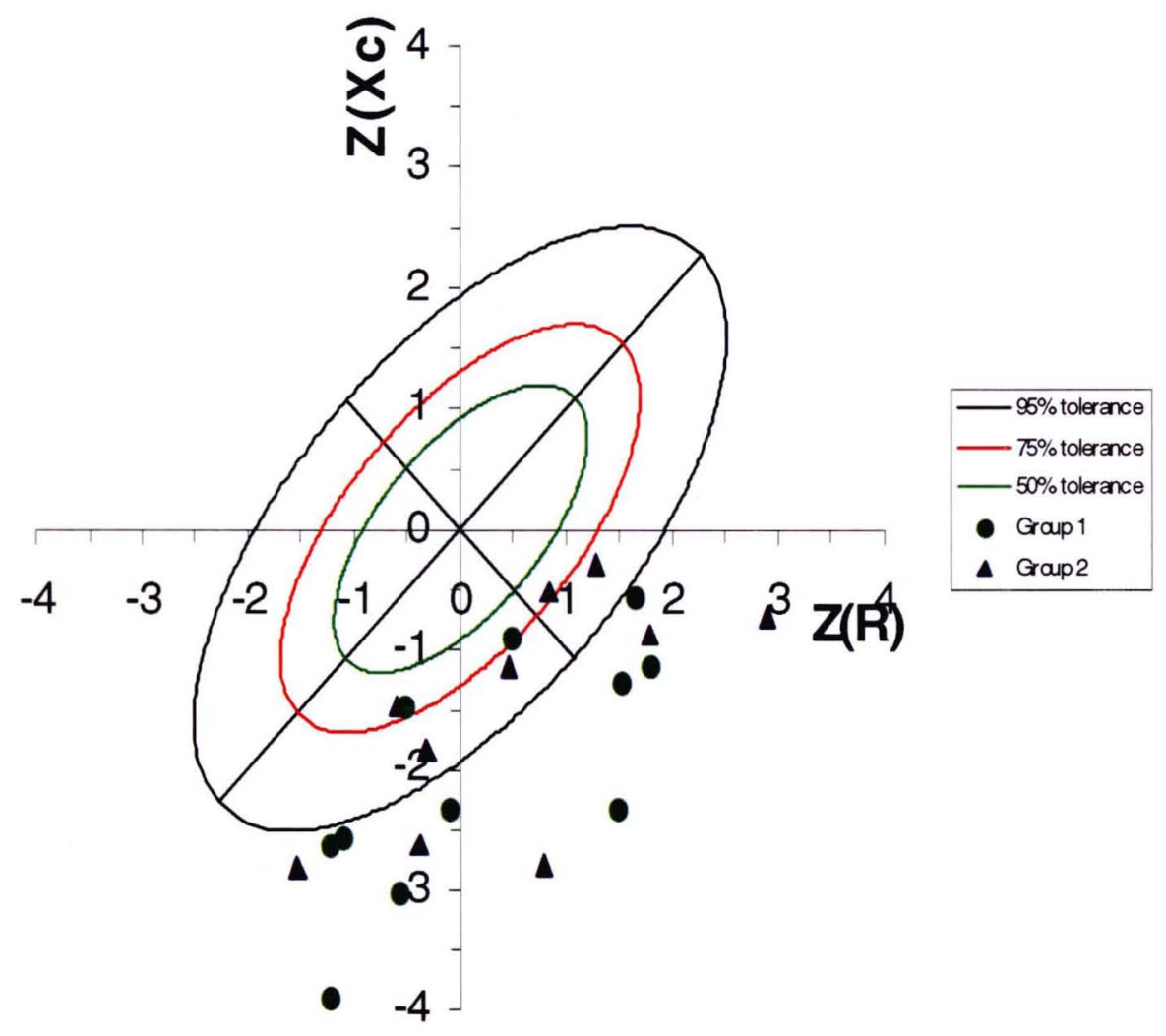

Grupo1= pré PTX; Grupo 2= pós PTX.

$\mathrm{Na}$ figura 5 , pode-se notar que após a PTX, houve um pequeno deslocamento dos pacientes da "esquerda inferior" para a "direita superior", isto é, houve uma diminuição da água corporal neste pacientes. Antes da PTX, apenas 02 pacientes encontravam-se dentro das elipses de tolerância, após a PTX 03 pacientes se locomoveram pra dentro das elipses, totalizando 05 pacientes.

Individualmente, observa-se deslocamento para a parte superior e direita do gráfico de 07 pacientes, indicando uma melhora clínica. Houve um deslocamento para a parte esquerda e inferior do gráfico de 2 pacientes, indicando uma piora clínica, e 01 paciente não apresentou alteração clínica. Não foi possível aplicar a análise vetorial das propriedades da BIA em 02 pacientes pois 1 se encontrava em cadeira de rodas, e o outro apresentou valores de $Z(X c)$ fora dos limites do gráfico ZXc-escore. 


\subsection{Ingestão Alimentar e Antropometria}

Correlacionando os dados de ingestão alimentar e antropometria antes e após a PTX, verifica-se que não houve correlação significativa entre os dados (Tabelas 6 e 7). Pode-se concluir, na amostra estudada, que a ingestão alimentar não teve participação nas alterações das medidas antropométricas comentadas anteriormente, e que estas alterações são atribuídas a fatores clínicos que não são relacionadas ao consumo alimentar.

Tabela 6 - Correlação entre dados de ingestão alimentar e antropometria, em pacientes em HD com IRC e HPT2, antes da PTX

\begin{tabular}{lcccc}
\hline $\begin{array}{c}\text { Correlcão de } \\
\text { Pearson }\end{array}$ & $\begin{array}{c}\text { Energia } \\
\text { (Kcal/dia) }\end{array}$ & $\begin{array}{c}\text { Proteína } \\
\text { (mg/dia) }\end{array}$ & $\begin{array}{c}\text { Cálcio } \\
\text { (mg/dia) }\end{array}$ & $\begin{array}{c}\text { Fósforo } \\
\text { (mg/dia) }\end{array}$ \\
\hline Peso seco (Kg) & $r=-0,08$ & $r=0,11$ & $r=-0,02$ & $r=-0,02$ \\
& $p=0,80$ & $p=0,72$ & $p=0,95$ & $p=0,95$ \\
IMC (Kg/m $\left.{ }^{2}\right)$ & $r=-0,29$ & $r=-0,06$ & $r=-0,24$ & $r=-0,19$ \\
& $p=0,36$ & $p=0,86$ & $p=0,44$ & $p=0,55$ \\
GC (Kg) & $r=-0,42$ & $r=-0,24$ & $r=-0,38$ & $r=-0,34$ \\
& $p=0,17$ & $p=0,45$ & $p=0,22$ & $p=0,28$ \\
MM (Kg) & $r=0,16$ & $r=0,32$ & $r=0,23$ & $r=0,20$ \\
& $p=0,61$ & $p=0,31$ & $p=0,48$ & $p=0,54$ \\
AF (graus) & $r=-0,04$ & $r=0,14$ & $r=-0,05$ & $r=0,09$ \\
& $p=0,91$ & $p=0,68$ & $p=0,89$ & $p=0,78$ \\
\hline
\end{tabular}

IMC= Indice de Massa Corporal; GC= Gordura Corporal; MM= Massa Magra; AF= Ángulo de Fase. 
Tabela 7 - Correlação entre dados de ingestão alimentar e antropometria, em pacientes em HD com IRC e HPT2, após 06 meses de PTX

\begin{tabular}{lcccc}
\hline $\begin{array}{c}\text { Correlação de } \\
\text { Pearson }\end{array}$ & $\begin{array}{c}\text { Energia } \\
\text { (Kcal/dia) }\end{array}$ & $\begin{array}{c}\text { Proteína } \\
\text { (mg/dia) }\end{array}$ & $\begin{array}{c}\text { Cálcio } \\
\text { (mg/dia) }\end{array}$ & $\begin{array}{c}\text { Fósforo } \\
\text { (mg/dia) }\end{array}$ \\
\hline Peso seco (Kg) & $r=0,43$ & $r=0,26$ & $r=0,15$ & $r=0,27$ \\
IMC (Kg/m ${ }^{2}$ ) & $p=0,18$ & $p=0,44$ & $p=0,66$ & $p=0,42$ \\
& $r=0,17$ & $r=0,006$ & $r=-0,07$ & $r=-0,17$ \\
GC (Kg) & $p=0,63$ & $p=0,98$ & $p=0,85$ & $p=0,96$ \\
MM (Kg) & $r=0,09$ & $r=-0,07$ & $r=0,11$ & $r=-0,09$ \\
& $p=0,79$ & $p=0,85$ & $p=0,77$ & $p=0,81$ \\
AF (graus) & $r=0,50$ & $r=0,39$ & $r=0,05$ & $r=0,42$ \\
& $p=0,14$ & $p=0,26$ & $p=0,89$ & $p=0,23$ \\
& $r=0,48$ & $r=0,28$ & $r=0,12$ & $r=0,31$ \\
& $p=0,16$ & $p=0,43$ & $p=0,75$ & $p=0,39$
\end{tabular}

IMC= Indice de Massa Corporal; GC= Gordura Corporal; MM= Massa Magra; AF= Ángulo de Fase.

\subsection{Exames bioquímicos}

Os exames bioquímicos relacionados à eficiência da diálise, estado nutricional e estado inflamatório (Tabela 8), os níveis séricos de uréia, creatinina e proteína $C$ reativa, apresentam-se elevados, em relação aos valores de referência, tanto antes como após a PTX. Além disso, não houve alteração estatisticamente significante após a cirurgia (de 127,5 $\pm 58,3 \mathrm{mg} / \mathrm{dl}$ para 99,1 $\pm 33,5 \mathrm{mg} / \mathrm{dl}$, de 9,9 \pm 4,6 mg/dl para $9,3 \pm 3,6 \mathrm{mg} / \mathrm{dl}$, e de $10,3 \pm 13,9 \mathrm{mcg} / \mathrm{ml}$ para $14,6 \pm 19,6 \mathrm{mcg} / \mathrm{ml}$, respectivamente).

Quanto aos niveis séricos de proteína total e albumina, estes se apresentam dentro dos valores de normalidade, e nota-se também, que houve uma melhora estatisticamente significante destes valores, após a PTX (de 7,0 I $0,9 \mathrm{~g} / \mathrm{dl}$ para $7,6 \pm 0,5 \mathrm{~g} / \mathrm{dl}$, e 3,9 $\pm 0,4 \mathrm{~g} / \mathrm{dl}$ para $4,2 \pm 0,6 \mathrm{~g} / \mathrm{dl}$ respectivamente) 
Tabela 8 - Exames bioquímicos relacionados à eficiência da diálise, estado nutricional e inflamação, de pacientes em HD com IRC e HPT2, antes e após a PTX.

\begin{tabular}{lccc}
\hline & Pré PTX & Pós PTX & $\begin{array}{l}\text { Valores de } \\
\text { referência }\end{array}$ \\
\hline Uréia & $127,5 \pm 58,3$ & $99,1 \pm 33,5$ & $10-45 \mathrm{mg} / \mathrm{dl}$ \\
Creatinina & $9,9 \pm 4,6$ & $9,3 \pm 3,6$ & $0,6-1,4 \mathrm{mg} / \mathrm{dl}$ \\
Proteína C reativa & $10,3 \pm 13,9$ & $14,6 \pm 19,6$ & $<5 \mathrm{mcg} / \mathrm{ml}$ \\
Proteína total & $7,0 \pm 0,9$ & $7,6 \pm 0,5^{*}$ & $6,0-8,0 \mathrm{~g} / \mathrm{dl}$ \\
Albumina & $3,9 \pm 0,4$ & $4,2 \pm 0,6^{*}$ & $3,5-5,0 \mathrm{~g} / \mathrm{dl}$ \\
\hline
\end{tabular}

" $p<0,05$ vs. pré PTX

Quanto aos exames bioquímicos relacionados ao metabolismo ósseo (Tabela 9), fósforo sérico apresentava concentração acima dos valores de referência antes da PTX, porém após a cirurgia, essa concentração diminuiu significantemente, passando então para os níveis de normalidade (de 6,7 $\pm 1,8$ $\mathrm{mg} / \mathrm{dl}$ para 4,5 $\pm 1,5 \mathrm{mg} / \mathrm{dl}$ ). Os níveis séricos de cálcio total, cálcio iônico e da $25(\mathrm{OH}) \mathrm{D}_{3}$ apresentaram-se dentro dos valores de referência, sem significativas alterações durante todo o estudo (de 9,3 $\pm 1,2 \mathrm{mg} / \mathrm{dl}$ para $8,5 \pm 1,1 \mathrm{mg} / \mathrm{dl}, 4,9 \pm$ $0,6 \mathrm{mg} / \mathrm{dl}$ para $4,6 \pm 1,0 \mathrm{mg} / \mathrm{dl}$, e $30,1 \pm 15,5 \mathrm{ng} / \mathrm{ml}$ para $37,8 \pm 20,7 \mathrm{ng} / \mathrm{ml}$, respectivamente).

Como era esperado, os níveis de PTHi, fosfatase alcalina total e fração óssea da fosfatase alcalina apresentavam-se bem acima dos valores de referência antes da PTX; entretanto, houve uma diminuição estatisticamente significante após os 06 meses de cirurgia (PTHi: de 1221, $6 \pm 685,1 \mathrm{pg} / \mathrm{ml}$ para 153,1 $\pm 189,2$ pg/ml; FAt: $542,2 \pm 835,4$ U/l para $111,9 \pm 68,2$ U/l; FAfo: $135,6 \pm 230,1$ U/l para $24,5 \pm 16,0 \mathrm{U} / \mathrm{l})$. 
Tabela 9 - Exames bioquímicos relacionados ao metabolismo ósseo

\begin{tabular}{lccc}
\hline & Pré PTX & Pós PTX & $\begin{array}{c}\text { Valores de } \\
\text { referência }\end{array}$ \\
\hline Cas $\mathbf{~ m g / m l ~}$ & $9,3 \pm 1,2$ & $8,5 \pm 1,1$ & $8,5-10,5 \mathrm{mg} / \mathrm{dl}$ \\
Ps $\mathbf{~ g} / \mathbf{m l}$ & $6,7 \pm 1,8$ & $4,5 \pm 1,5^{\star *}$ & $2,3-4,6 \mathrm{mg} / \mathrm{dl}$ \\
Cai $\mathbf{~ m g / m l ~}$ & $4,9 \pm 0,6$ & $4,6 \pm 1,0$ & $4,64-5,28 \mathrm{mg} / \mathrm{dl}$ \\
25(OH)D $\mathbf{~ n g / m l ~}$ & $30,1 \pm 15,5$ & $37,8 \pm 20,7$ & $8,9-46,7 \mathrm{ng} / \mathrm{ml}$ \\
PTHi pg/ml & $1221,6 \pm 685,1$ & $153,1 \pm 189,2^{* *}$ & $11-62 \mathrm{pg} / \mathrm{ml}$ \\
FAt U/l & $542,2 \pm 835,4$ & $111,9 \pm 68,2^{* *}$ & $32-104 \mathrm{U} / \mathrm{l}$ \\
FAfo U/l & $135,6 \pm 230,1$ & $24,5 \pm 16,0^{*}$ & $6,4-20,8 \mathrm{U} / \mathrm{l}$
\end{tabular}

Cas= cálcio sérico, $\mathrm{Ps}=$ fósforo sérico, Cai= cálcio iônico, 25(OH)D3= vitamina $\mathrm{D}, \mathrm{PTH}=$ paratormônio intacto, FAt= fosfatase alcalina total, FAfo= fração óssea da fosfatase alcalina ${ }^{*} p<0,05$

${ }^{\star *} p<0,001$

$\mathrm{Na}$ Tabela 10, encontram-se as correlações entre iPTH, Fosfatase Alcalina total (FAt) e fração óssea (FAfo), vitamina $D\left(25(\mathrm{OH}) \mathrm{D}_{3}\right)$, cálcio e fósforo séricos, antes e após a PTX.

Antes da PTX, observa-se a presença de correlação positiva entre a FAt e a FAfo, o que é completamente normal já que a FAfo é uma fração óssea da FAt. Houve uma correlação negativa entre a FAt e a FAfo com o Ps.

Após os 06 meses de PTX, a correlação entre FAt e a FAfo continua positiva e significante. Entretanto não houve correlação entre a FAfo com o Ps. 
Tabela 10- Correlação entre marcadores bioquímicos do metabolismo ósseo de pacientes em HD com IRC e HPT2, antes e 06 meses após a PTX.

\begin{tabular}{|c|c|c|c|c|c|c|}
\hline $\begin{array}{l}\text { Correlação } \\
\text { de Pearson }\end{array}$ & $\begin{array}{c}\text { IPTH } \\
(\mathrm{pg} / \mathrm{ml})\end{array}$ & $\begin{array}{l}\text { FAt } \\
(U / I)\end{array}$ & $\begin{array}{l}\text { FAfo } \\
\text { (U/I) }\end{array}$ & $\begin{array}{c}\text { Cas } \\
(\mathrm{mg} / \mathrm{ml})\end{array}$ & $\begin{array}{c}\text { Ps } \\
(\mathrm{mg} / \mathrm{ml})\end{array}$ & $\begin{array}{c}\text { Vit D } \\
(\mathrm{ng} / \mathrm{ml})\end{array}$ \\
\hline \multirow[t]{2}{*}{ iPTH (pg/ml) } & - & $r=0,03$ & $r=0,02$ & $r=-0,17$ & $r=-0,33$ & $r=-0,26$ \\
\hline & & $p=0,94$ & $p=0,97$ & $p=0,61$ & $p=0,30$ & $p=0,47$ \\
\hline \multirow[t]{2}{*}{ FAt (U/I) } & $r=0,09$ & - & $r=0,99^{\star \star}$ & $r=-0,18$ & $r=-0,86^{\star \star}$ & $r=-0,11$ \\
\hline & $p=0,77$ & & $p=0,000$ & $p=0,58$ & $p=0,000$ & $p=0,77$ \\
\hline \multirow[t]{2}{*}{ FAfo (U/I) } & $r=0,16$ & $r=0,89^{\star \star}$ & - & $r=-0,15$ & $r=-0,89^{\star \star}$ & $r=-0,13$ \\
\hline & $p=0,62$ & $p=0,000$ & & $p=0,71$ & $p=0,001$ & $p=0,74$ \\
\hline \multirow[t]{2}{*}{ Cas (mg/ml) } & $r=-0,28$ & $r=-0,04$ & $r=-0,15$ & - & $r=0,19$ & $r=0,06$ \\
\hline & $p=0,38$ & $p=0,90$ & $p=0,65$ & & $p=0,54$ & $p=0,87$ \\
\hline \multirow[t]{2}{*}{ Ps $(\mathrm{mg} / \mathrm{ml})$} & $r=0,30$ & $r=-0,61^{*}$ & $r=-0,45$ & $r=0,05$ & - & $r=0,16$ \\
\hline & $p=0,34$ & $p=0,04$ & $p=0,15$ & $p=0,88$ & & $p=0,66$ \\
\hline \multirow[t]{2}{*}{ Vit $D(n g / m l)$} & $r=-0,42$ & $r=-0,56$ & $r=-0,39$ & $r=-0,28$ & $r=0,25$ & - \\
\hline & $p=0,17$ & $p=0,06$ & $p=0,21$ & $p=0,38$ & $p=0,43$ & \\
\hline
\end{tabular}

$\overline{\mathrm{iPTH}}=$ paratormônio intacto; $\mathrm{FAt}=$ fosfatase alcalina total; $\mathrm{FAfo}=$ fração óssea da fosfatase alcalina; Cas= cálcio sérico; Ps= fósforo sérico.

${ }^{*} \mathrm{p}<0,05$

** $p<0,001$

$\rightarrow$ Antes da PTX

$\rightarrow 06$ meses após PTX

Tanto antes como após a PTX, não houve correlação entre a proteína $C$ reativa (PCR) com o iPTH (pré PTX: $r=-0,26, p=0,48$; pós $P T X: r=0,49 ; p=0,13$ ) 


\subsection{Exames bioquímicos e ingestão alimentar}

Correlacionando os dados bioquímicos com a ingestão alimentar, não foi encontrada significância entre os dados, tanto antes como após a PTX (Tabelas 11 e 12).

Tabela 11- Correlação entre exames bioquímicos e ingestão alimentar de pacientes em HD com IRC e HPT2, antes da PTX.

\begin{tabular}{|c|c|c|c|c|}
\hline $\begin{array}{l}\text { Correlação de } \\
\text { Pearson }\end{array}$ & $\begin{array}{c}\text { Energia } \\
\text { (Kcal/dia) }\end{array}$ & $\begin{array}{l}\text { Proteína } \\
\text { (mg/dia) }\end{array}$ & $\begin{array}{c}\text { Cálcio } \\
\text { (mg/dia) }\end{array}$ & $\begin{array}{l}\text { Fósforo } \\
\text { (mg/dia) }\end{array}$ \\
\hline \multirow[t]{2}{*}{ iPTH (pg/ml) } & $r=0,02$ & $r=-0,19$ & $r=-0,21$ & $r=-0,09$ \\
\hline & $p=0,95$ & $p=0,55$ & $p=0,52$ & $p=0,77$ \\
\hline \multirow[t]{2}{*}{ FAt (U/I) } & $r=-0,09$ & $r=-0,02$ & $r=-0,15$ & $r=0,08$ \\
\hline & $p=0,77$ & $p=0,96$ & $p=0,65$ & $p=0,81$ \\
\hline \multirow[t]{2}{*}{ FAfo (U/I) } & $r=-0,14$ & $r=-0,05$ & $r=-0,21$ & $r=0,06$ \\
\hline & $p=0,72$ & $p=0,89$ & $p=0,60$ & $p=0,88$ \\
\hline \multirow[t]{2}{*}{ Cas (mg/dl) } & $r=0,24$ & $r=0,07$ & $r=0,29$ & $r=0,02$ \\
\hline & $p=0,45$ & $p=0,82$ & $p=0,37$ & $p=0,96$ \\
\hline \multirow[t]{2}{*}{ Ps (mg/dl) } & $r=0,01$ & $r=0,01$ & $r=0,20$ & $r=-0,07$ \\
\hline & $p=0,98$ & $p=0,97$ & $p=0,53$ & $p=0,84$ \\
\hline \multirow[t]{2}{*}{ Vit D (ng/ml) } & $r=0,14$ & $r=0,13$ & $r=0,09$ & $r=0,04$ \\
\hline & $p=0,70$ & $p=0,72$ & $p=0,81$ & $p=0,92$ \\
\hline \multirow[t]{2}{*}{ Prot. total (g/dl) } & $r=0,001$ & $r=-0,17$ & $r=-0,12$ & $r=-0,25$ \\
\hline & $p=0,99$ & $p=0,66$ & $p=0,76$ & $p=0,52$ \\
\hline \multirow[t]{2}{*}{ Albumina (g/dl) } & $r=0,09$ & $r=-0,16$ & $r=-0,01$ & $r=-0,21$ \\
\hline & $p=0,83$ & $p=0,69$ & $p=0,99$ & $p=0,59$ \\
\hline
\end{tabular}

$\mathrm{iPTH}=$ paratormônio intacto; $\mathrm{FAt}=$ fosfatase alcalina total; $\mathrm{FAfo}=$ fração óssea da fosfatase alcalina; Cas= cálcio sérico; $P S=$ fósforo sérico; Vit $D=$ vitamina $D ;$ Prot. total= proteína total 
Tabela 12- Correlação entre exames bioquímicos e ingestão alimentar de pacientes em HD com IRC e HPT2, após 06 meses da PTX.

\begin{tabular}{lcccc}
\hline $\begin{array}{l}\text { Correlação de } \\
\text { Pearson }\end{array}$ & $\begin{array}{c}\text { Energia } \\
\text { (Kcal/dia) }\end{array}$ & $\begin{array}{c}\text { Proteína } \\
\text { (mg/dia) }\end{array}$ & $\begin{array}{c}\text { Cálcio } \\
\text { (mg/dia) }\end{array}$ & $\begin{array}{c}\text { Fósforo } \\
\text { (mg/dia) }\end{array}$ \\
\hline iPTH (pg/ml) & $r=0,31$ & $r=0,14$ & $r=0,60$ & $r=0,22$ \\
& $p=0,36$ & $p=0,69$ & $p=0,05$ & $p=0,51$ \\
FAt (U/I) & $r=-0,39$ & $r=-0,23$ & $r=-0,07$ & $r=-0,25$ \\
& $p=0,24$ & $p=0,50$ & $p=0,83$ & $p=0,46$ \\
FAfo (U/) & $r=-0,20$ & $r=-0,20$ & $r=-0,04$ & $r=-0,17$ \\
& $p=0,55$ & $p=0,56$ & $p=0,92$ & $p=0,62$ \\
Cas (mg/dl) & $r=0,08$ & $r=0,26$ & $r=0,09$ & $r=0,10$ \\
& $p=0,82$ & $p=0,45$ & $p=0,79$ & $p=0,77$ \\
Ps (mg/d) & $r=0,42$ & $r=0,28$ & $r=0,40$ & $r=0,41$ \\
& $p=0,19$ & $p=0,41$ & $p=0,22$ & $p=0,22$ \\
Vit D (ng/ml) & $r=0,39$ & $r=0,36$ & $r=-0,08$ & $r=0,33$ \\
& $p=0,23$ & $p=0,28$ & $p=0,82$ & $p=0,32$ \\
Prot. total (g/dl) & $r=0,26$ & $r=0,33$ & $r=0,29$ & $r=0,15$ \\
& $p=0,44$ & $p=0,33$ & $p=0,39$ & $p=0,66$ \\
Albumina (g/dl) & $r=0,25$ & $r=0,33$ & $r=-0,08$ & $r=0,14$ \\
& $p=0,47$ & $p=0,32$ & $p=0,81$ & $p=0,68$ \\
\hline
\end{tabular}

$\mathrm{iPTH}=$ paratormônio intacto; $\mathrm{FAt}=$ fosfatase alcalina total; $F A f o=$ fraçăo óssea da fosfatase alcalina; Cas= cálcio sérico; $\mathrm{Ps}=$ fósforo sérico; Vit $\mathrm{D}=$ vitamina $\mathrm{D}$; Prot. total= proteína total.

\subsection{Exames bioquímicos e composição corporal}

Correlacionando os dados bioquímicos com os da composição corporal dos pacientes estudados, antes e após a PTX (Tabelas 13 e 14), observa-se que antes da PTX, há presença de correlação negativa entre o IPTH e o peso seco, mostrando que quanto maiores os níveis de PTH, menor é o peso corporal do 
paciente. Também há presença de correlação negativa entre a FAfo e a MM. Observa-se ainda, correlação negativa entre o iPTH e a GC, portanto quanto maiores os níveis séricos de iPTH menor será a GC dos pacientes com IRC e HPT2.

Após os 06 meses da realização da PTX, encontra-se correlação positiva entre o peso seco e o Ps. Este achado talvez ocorra devido a normalização do metabolismo do Ca/P/PTH nos pacientes estudados.

Tabela 13- Correlação entre exames bioquímicos e dados da composição corporal dos pacientes estudados, antes da PTX.

\begin{tabular}{lccccc}
\hline $\begin{array}{l}\text { Correlação de } \\
\text { Pearson }\end{array}$ & $\begin{array}{c}\text { Peso seco } \\
(\mathbf{K g})\end{array}$ & $\begin{array}{c}\text { IMC } \\
\left(\mathbf{K g} / \mathbf{m}^{2}\right)\end{array}$ & $\begin{array}{c}\text { GC } \\
\mathbf{( K g )}\end{array}$ & $\begin{array}{c}\text { MM } \\
\mathbf{( K g )}\end{array}$ & $\begin{array}{c}\text { AF } \\
\text { (graus) }\end{array}$ \\
\hline iPTH (pg/ml) & $r=-0,63^{*}$ & $r=-0,56$ & $r=-0,69^{*}$ & $r=-0,46$ & $r=-0,40$ \\
& $p=0,03$ & $p=0,06$ & $p=0,01$ & $p=0,13$ & $p=0,20$ \\
FAt (U/l) & $r=-0,37$ & $r=-0,22$ & $r=-0,10$ & $r=-0,45$ & $r=-0,06$ \\
& $p=0,24$ & $p=0,49$ & $p=0,76$ & $p=0,15$ & $p=0,85$ \\
FAfo (U/l) & $r=-0,53$ & $r=-0,30$ & $r=-0,08$ & $r=-0,68^{*}$ & $r=-0,08$ \\
Cas (mg/dl) & $p=0,15$ & $p=0,43$ & $p=0,84$ & $p=0,04$ & $p=0,84$ \\
& $r=-0,16$ & $r=-0,10$ & $r=0,07$ & $r=-0,25$ & $r=-0,40$ \\
Ps (mg/dl) & $p=0,63$ & $p=0,76$ & $p=0,84$ & $p=0,43$ & $p=0,20$ \\
& $r=0,36$ & $r=0,23$ & $r=0,18$ & $r=0,40$ & $r=0,24$ \\
Prot. total (g/d) & $r=0,18$ & $r=0,15$ & $r=0,40$ & $r=-0,01$ & $r=0,15$ \\
& $p=0,64$ & $p=0,69$ & $p=0,29$ & $p=0,99$ & $p=0,70$ \\
Albumina (g/dl) & $r=0,39$ & $r=0,19$ & $r=0,29$ & $r=0,36$ & $r=0,38$ \\
& $p=0,30$ & $p=0,62$ & $p=0,45$ & $p=0,34$ & $p=0,31$ \\
\hline
\end{tabular}

$\mathrm{iPTH}=$ paratormônio intacto; $\mathrm{FAt}=$ fosfatase alcalina total $\mathrm{FAfo}=$ fração óssea da fosfatase alcalina; Cas= cálcio sérico; $\mathrm{PS}=$ fósforo sérico; Prot. total= proteína total; $\mathrm{IMC}=$ Índice de Massa Corporal; $\mathrm{GC}=$ Gordura Corporal; $\mathrm{MM}=$ Massa Magra; $\mathrm{AF}=$ Ângulo de Fase. ${ }^{*} \mathrm{p}<0,05$ 
Tabela 14- Correlação entre exames bioquímicos e dados da composição corporal de pacientes em HD com IRC e HPT2, após 06 meses de PTX.

\begin{tabular}{lccccc}
\hline $\begin{array}{l}\text { Correlação de } \\
\text { Pearson }\end{array}$ & $\begin{array}{c}\text { Peso seco } \\
\mathbf{( K g )}\end{array}$ & $\begin{array}{c}\text { IMC } \\
\left(\mathbf{K g} / \mathbf{m}^{2}\right)\end{array}$ & $\begin{array}{c}\text { GC } \\
(\mathbf{K g})\end{array}$ & $\begin{array}{c}\text { MM } \\
(\mathbf{K g})\end{array}$ & $\begin{array}{c}\text { AF } \\
\text { (graus) }\end{array}$ \\
\hline iPTH (pg/mI) & $r=0,02$ & $r=-0,03$ & $r=0,36$ & $r=-0,23$ & $r=0,17$ \\
& $p=0,95$ & $p=0,93$ & $p=0,28$ & $p=0,50$ & $p=0,61$ \\
FAt (U/l) & $r=-0,47$ & $r=-0,34$ & $r=-0,21$ & $r=-0,48$ & $r=-0,18$ \\
& $p=0,13$ & $p=0,28$ & $p=0,54$ & $p=0,14$ & $p=0,59$ \\
FAfo (U/) & $r=-0,30$ & $r=-0,22$ & $r=-0,12$ & $r=-0,30$ & $r=0,20$ \\
& $p=0,35$ & $p=0,50$ & $p=0,73$ & $p=0,36$ & $p=0,55$ \\
Cas (mg/dl) & $r=0,49$ & $r=0,53$ & $r=0,59$ & $r=0,27$ & $r=-0,04$ \\
& $p=0,11$ & $p=0,07$ & $p=0,05$ & $p=0,42$ & $p=0,91$ \\
Ps (mg/dl) & $r=0,64^{*}$ & $r=0,51$ & $r=0,47$ & $r=0,44$ & $r=0,52$ \\
& $p=0,03$ & $p=0,09$ & $p=0,15$ & $p=0,17$ & $p=0,10$ \\
Prot. total (g/dl) & $r=0,09$ & $r=0,17$ & $r=0,47$ & $r=-0,25$ & $r=0,10$ \\
& $p=0,77$ & $p=0,59$ & $p=0,15$ & $p=0,45$ & $p=0,77$ \\
Albumina (g/dl) & $r=0,37$ & $r=0,39$ & $r=0,36$ & $r=0,26$ & $r=0,48$ \\
& $p=0,24$ & $p=0,21$ & $p=0,28$ & $p=0,43$ & $p=0,14$ \\
\hline
\end{tabular}

$\overline{\mathrm{IPTH}}=$ paratormônio intacto; $\mathrm{FAt}=$ fosfatase alcalina total; $\mathrm{FAfo}=$ fração óssea da fosfatase alcalina; Cas= cálcio sérico; Ps= fósforo sérico; Prot. total= proteina total; $1 \mathrm{MC}=$ Índice de Massa Corporal; $\mathrm{GC}=$ Gordura Corporal; MM= Massa Magra; $\mathrm{AF}=$ Ângulo de Fase. ${ }^{*} \mathrm{p}<0,05$

Destacando a influência do iPTH na composição corporal dos pacientes com HPT2, observa-se que antes da cirurgia, os níveis elevados de PTH (1221,6 \pm $685,1 \mathrm{pg} / \mathrm{ml}$ ) exerciam efeito negativo na gordura corporal em $\mathrm{Kg}$. Após a queda acentuada dos níveis séricos de PTH, este efeito não foi significante, como ilustrado nas Figuras 6 e 7 . 
Figura 6 - Correlação entre iPTH e Gordura Corporal (GC) de pacientes em HD com IRC e HPT2, antes da PTX

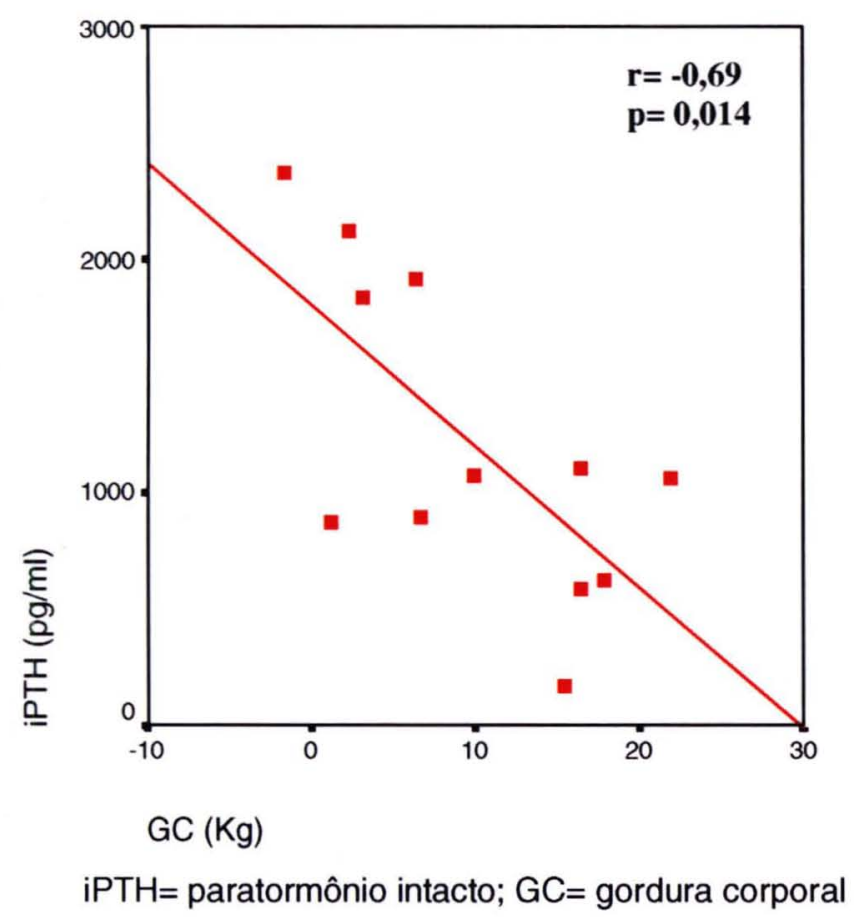

Figura 7 - Correlação entre iPTH e Gordura Corporal (GC) de pacientes em HD com IRC e HPT2, após 06 meses de PTX

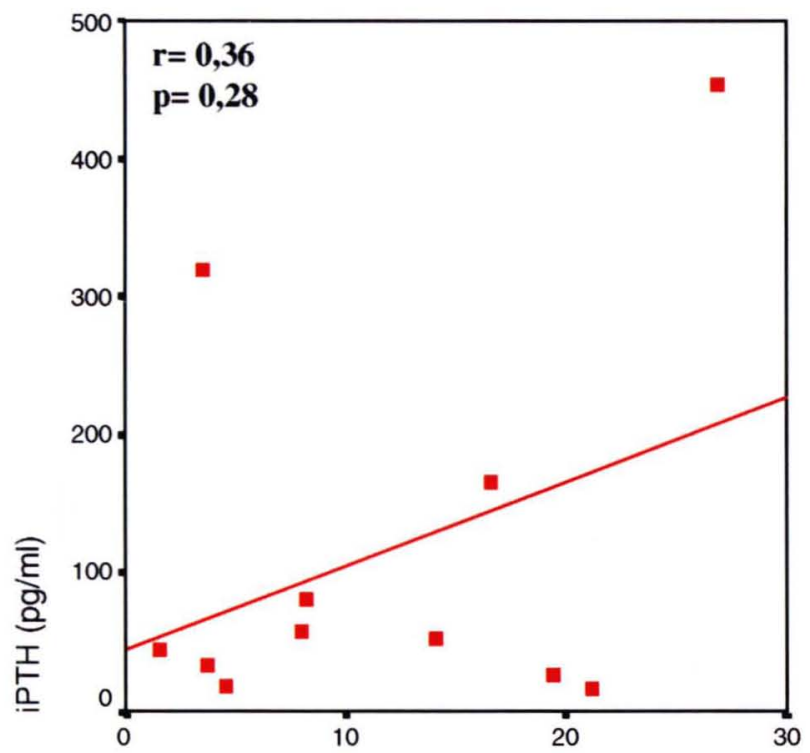

$\mathrm{GC}(\mathrm{Kg})$

iPTH= paratormônio sérico; GC= gordura corporal. 
Discussão 


\section{DISCUSSÃO}

\subsection{Ingestão alimentar}

A desnutrição energético-protéica é muito freqüente em pacientes com IRC. Estima-se que a desnutrição esteja presente em $40 \%$ dos pacientes com IRC em hemodiálise ${ }^{8,26}$. Entre as múltiplas causas destaca-se a anorexia, levando a ingestão deficiente de nutrientes ${ }^{1,92,135}$.

Para evitar a desnutrição nestes pacientes, orientação nutricional adequada tem sido recomendada. Em nosso meio, Cuppari et al. ${ }^{25}$, estudando 100 pacientes com IRC em HD, com o objetivo de caracterizar o estado nutricional de pacientes em programa de hemodiálise através de inquéritos alimentares, observaram que a ingestão a ingestão calórica média estava reduzida em $24 \%$ quando comparada com a ingestão calórica recomendada para pacientes em hemodiálise (35 Kcal/Kg/dia). Observaram também uma ingestão média insuficiente de proteína, em torno de $1,0 \mathrm{~g} / \mathrm{Kg} /$ dia, quando o recomendado é no minimo $1,2 \mathrm{~g} / \mathrm{Kg} / \mathrm{dia}$. Quanto ao estado nutricional, observou-se a prevalência de desnutrição leve e moderada.

Pacientes com IRC e HPT2 foram avaliados por Rezende et al. ${ }^{104}$. Os autores observaram que as ingestões médias de energia, proteína, e de cálcio também estavam abaixo do recomendado em ambos os grupos. Um estudo preliminar realizado no Ambulatório de Osteodistrofia Renal do Hospital das Clínicas ${ }^{99}$ encontrou ingestão de energia e cálcio abaixo das recomendações do KJDOQI em pacientes com HPT2 leve e severo, e ingestão protéica inadequada apenas nos pacientes com HPT2 severo.

No presente estudo, a ingestão média de energia proveniente da dieta antes da PTX, também se encontrava abaixo do recomendado $(30,8 \pm 13,3$ $\mathrm{Kcal} / \mathrm{Kg} / \mathrm{dia}$ ); porém, após a PTX o consumo calórico aumentou para $35,1 \pm 9,5$ $\mathrm{Kcal} / \mathrm{Kg} / \mathrm{dia}$, ficando então adequada para estes pacientes.

Mesmo o iPTH não apresentando correlação com a ingestão calórica, e esta ser estatisticamente semelhante antes e após a PTX neste estudo, o elevado 
nível de iPTH antes da PTX, através de suas complicações metabólicas (catabolismo, dores, dificuldade de locomoção, etc.), pode ter interferido no apetite destes pacientes, uma vez que os mesmos relatavam alterações na ingestão alimentar.

O controle do fósforo sérico é muito importante em pacientes com HPT2, pois inibe diretamente a proliferação celular das glândulas paratireóides ${ }^{31 .}$ 57. Uma das formas de manter os valores de fósforo sérico dentro dos limites de normalidade para pacientes em diálise $(3,5$ a $5,5 \mathrm{mg} / \mathrm{dl})$ é através da restrição de fósforo da dieta, o que entra em conflito com a necessidade diária de ingestão protéica para estes pacientes $5,15,23,57,90,111$, uma vez que os alimentos ricos em fósforo são também ricos em proteína. Apesar dos niveis séricos de fósforo estarem elevados antes da PTX, os pacientes apresentaram ingestão de fósforo e proteína adequada, talvez devido à orientação nutricional que os pacientes receberam enquanto aguardavam a realização da PTX.

Além disso, após a PTX, houve um aumento da ingestão de fósforo para $17,4 \pm 6,8 \mathrm{mg} / \mathrm{Kg} /$ dia, devido o aumento da ingestão de alimentos ricos em fósforo ser recomendado, não apenas visando o equilíbrio no balanço da $\mathrm{Ca} / \mathrm{P} / \mathrm{PTH}$, mas também para recuperar os efeitos deletérios do catabolismo protéico conseqüente ao PTH elevado.

A ingestão de cálcio nestes pacientes, apesar de ter aumentado significantemente após a PTX, também devido ao estímulo para ingerir leite e derivados, estava deficiente antes da cirurgia $(382,2 \pm 209,6 \mathrm{mg} / \mathrm{dia})$ e após a PTX manteve-se entre 500 e $1200 \mathrm{mg} / \mathrm{dia}(656,6 \pm 313,8 \mathrm{mg} / \mathrm{dia})$; entretanto, não podemos afirmar que esta ingestão está colocando o paciente em risco de calcificação vascular, uma vez que a ingestão do quelante varia de acordo com os exames laboratoriais mensais. Alimentos ricos em cálcio, como leite e derivados, normalmente são restringidos na dieta de pacientes com HPT2 severo, pois estes alimentos também são ricos em fósforo, assim ocorre deficiente ingestão de cálcio nestes pacientes. Este fato ressalta a importância de uma correta prescrição na utilização de suplementos. 


\subsection{Antropometria}

\section{- IMC e componentes da BIA}

A IRC é um estado catabólico, caracterizado pela redução da gordura corporal e de anormalidades do metabolismo protéico, gerando perda progressiva da massa magra e de proteína muscular. A desnutrição crônica acompanhada de intenso catabolismo protéico encontra-se geralmente presente na síndrome urêmica e no HPT2, elevando a incidência de morbidade e mortalidade nesses pacientes. Dessa forma, a manutenção do estado nutricional adequado é fundamental ${ }^{88,96,105}$.

A antropometria é considerada um importante componente da avaliação do estado nutricional e instrumento valioso para o monitoramento de mudanças e para intervenção dietética.

O índice de massa corporal, apesar de sua facilidade de aplicação e ampla utilização, não é um método fidedigno para pacientes em HD devido as constantes alterações no volume hidrico dos mesmos. Assim, métodos mais precisos na avaliação antropométrica de pacientes em HD são recomendados, como, por exemplo, a impedância bioelétrica.

A impedância bioelétrica (BIA) é um método simples, não invasivo, rápido, sensivel, indolor, relativamente preciso, usado para avaliar a composição corporal, por meio da passagem de corrente elétrica de baixa amplitude, e tem sido muito utilizada em pacientes com IRC em HD 38,39,43,131.

Como os pacientes deste estudo encontravam-se estáveis, sem complicações adicionais como infecções, perda de peso acentuada nos últimos 6 meses após a cirurgia, o IMC foi realizado apenas como "screening" e classificação geral do estado nutricional. A média do IMC antes e após a PTX também estava dentro da faixa de normalidade ${ }^{132}$, sendo que pequena porcentagem foi classificada com baixo peso ( $20 \%$ ) e com obesidade $(\cong 10 \%)$. 
Porém, avaliando os diferentes compartimentos corporais antes da PTX, a maioria dos pacientes $(86,6 \%)$ apresentava baixa distribuição de GC em $\mathrm{Kg}$, e que depois da cirurgia esse número caiu para $71,4 \%$. Assim, tanto antes como após a PTX, foi encontrado déficit no compartimento gorduroso.

Quanto a MM em Kg, os achados diferem da GC, antes da cirurgia $27 \%$ apresentavam baixa distribuição de $\mathrm{MM}, 7 \%$ apresentavam distribuição normal e $66 \%$ apresentavam distribuição superior ao considerado normal. Após a PTX, a baixa distribuição de $\mathrm{MM}$ aumentou para $43 \%$, a porcentagem dos pacientes que apresentavam distribuição normal de MM continuou igual à antes da PTX, e os pacientes com valor superior ao esperado diminuiu para 50\%. Estas alterações podem ter sido influenciadas pela variação no volume hídrico corporal destes pacientes.

Em relação à água corporal total (ACT) em litros, antes da PTX 93\% dos pacientes apresentavam distribuição normal de ACT e apenas $7 \%$ apresentavam distribuição excessiva. Após a PTX, 79\% dos pacientes apresentavam distribuição normal de ACT e $21 \%$ passaram a apresentar baixa distribuição, entretanto não houve mais a presença de distribuição excessiva de água. Nenhum paciente apresentou excesso de água intra celular (AIC) antes e após a PTX, sendo que de $60 \%$ aumentou para $79 \%$ a distribuição normal de AIC após a PTX. Quanto à água extra celular (AEC), verifica-se que de $27 \%$ diminuiu para $7 \%$ a distribuição excessiva de AEC para após a PTX. Nota-se que houve uma melhora na distribuição de água corporal nos pacientes após a realização da PTX.

Os resultados do presente estudo, após a PTX, estão de acordo com o observado por Monteiro et al. ${ }^{88}$, que avaliando o estado nutricional de pacientes em HD utilizando os compartimentos corporais obtidos pela BIA, verificaram que o IMC dos pacientes estudados estava dentro da faixa de normalidade, que a massa magra (MM) estava levemente reduzida quando comparada a individuos normais, onde a média encontrada é de $49 \mathrm{Kg}$, e que os pacientes apresentavam um déficit no compartimento gorduroso. Kamimura et al. ${ }^{61}$ e Woodrow et al. ${ }^{131}$, avaliando pacientes em hemodiálise, também verificaram em seus respectivos estudos, que 
a média do IMC dos pacientes estudados estava dentro da faixa de normalidade, para indivíduos normais.

Avaliando então os efeitos da PTX nos compartimentos corporais, gordura corporal, massa muscular e água corporal, observa-se que após 6 meses de cirurgia houve pequena melhora na porcentagem dos pacientes que apresentavam baixa distribuição de gordura corporal. Houve aumento na porcentagem dos pacientes que apresentavam baixa distribuição de massa magra, talvez devido à redução na água corporal total.

\section{- Propriedades da BIA}

Medidas de composição corporal, obtidas pela BIA em pacientes em diálise requerem muita atenção para minimizar a variabilidade da técnica. Devido a dificuldades com hidratação tecidual e derivações matemáticas que definem os compartimentos corporais, alguns autores têm avaliado a relação entre as medidas das propriedades da BIA e seus resultados nos pacientes ${ }^{39}$. Medidas das propriedades da BIA como a $\mathrm{R}, \mathrm{Xc}$, e os valores do $\phi$, tem sido cada vez mais usados na prática clínica ${ }^{100,103}$.

Dumler \& Kilates ${ }^{38}$, comparando os parâmetros convencionais e vetoriais da BIA em pacientes renais crônicos em HD com a população de NHANES III, verificaram que não houve diferença significante quanto a ACT entre os grupos, porém a AIC foi $9 \%$ menor e a AEC foi $17 \%$ maior nos pacientes renais crônicos. A MM e a GC foi significantemente menor nos pacientes renais. Os valores de resistência, reactância e do ângulo de fase foram significantemente diferentes entre os grupos. Os valores de $\mathrm{R}$ foram $3 \%$ menores na população contida no NHANES III, e os valores de XC e do $\phi$ foram $26 \%$ e $28 \%$ respectivamente menores nos pacientes renais em HD. Ajustando os valores médios de $\mathrm{R}$ e $\mathrm{Xc}$ pela altura $(\mathrm{R} / \mathrm{H}$ e $\mathrm{Xc} / \mathrm{H})$ dos dois grupos e aplicando-os em um gráfico $\mathrm{RXc}$, verificaram que o grupo dos renais crônicos apresentavam menor massa celular corporal e maior fluido extracelular do que a população contida no 
NHANES III. Os autores concluíram que as análises separadas dos componentes e das propriedades da BIA foram semelhantes.

O ângulo de fase $(\phi)$, medida direta de estabilidade e saúde celular que reflete mudanças de água intra e extra celular, pode ser conceitualizado como um valor resumido da BIA. Vários estudos têm mostrado que o $\phi$ é um significante preditor de sobrevida em pacientes com síndrome da imunodeficiência adquirida $e$ em pacientes com IRC ${ }^{19,76,97}$. Essas observações sugerem que o uso do $\phi$, como potente preditor de mortalidade, pode identificar indivíduos em risco sendo beneficiados com o emprego rápido e intenso de uma terapia adequada.

Johansen et al ${ }^{58}$, analisando o estado nutricional de pacientes renais em hemodiálise durante 12 meses, verificou uma queda significativa nos valores do $\phi$ durante o tempo do estudo. O valor do $\phi$ no início do estudo era de $5,3 \pm 1,5^{\circ}$, e notou-se uma queda gradativa e significante de $0,042 \pm 0,012^{\circ}$ por mês.

No presente estudo, os valores do $\phi$ aumentaram significantemente. Antes da PTX, o valor médio do $\phi\left(5,0 \pm 1,4^{\circ}\right)$ apresentava risco de mortalidade para os pacientes (definido como $\phi<0 u=5^{\circ}$ ), após a PTX esse risco não esteve mais presente, pois o valor médio do $\phi$ aumentou para $5,6 \pm 1,3^{\circ}$. Apesar de não ter havido correlação entre o $\phi$ e o $\mathrm{iPTH}$, indiretamente a queda dos níveis séricos de PTH contribuíram para uma melhora dos valores do $\phi$.

Os tecidos magros são altamente condutores de corrente elétrica, por conter grande quantidade de água e eletrólitos, portanto apresentam baixa resistência. Por outro lado, a gordura e os ossos, são pobres condutores, com menor quantidade de fluídos e eletrólitos e maior resistência elétrica. Portanto a $R$ é inversamente proporcional à quantidade de fluídos presentes no organismo ${ }^{92}$. Já a Xc reflete o desempenho dinâmico da estrutura ou massa biologicamente ativa das membranas celulares. Simplificando a $\mathrm{Xc}$ se relaciona com o balanço hídrico extra e intra celular, estando numa dependência normal da membrana celular. Em humanos a Xc é um indicador de massa corpórea magra e intracelular 100 
A R e a Xc, assim como o $\phi$, também apresentaram aumento após a PTX, porém apenas o aumento da $X_{c}$ foi estatisticamente significante. Tomando como base o que foi descrito acima, o aumento da $X_{c}$ pode ser explicado pela diminuição de massa magra e fluídos corporais, ou então pelo aumento da gordura corporal nestes pacientes, sendo esta a explicação mais provável, devido ao seu aumento estatisticamente significante. $A R$, apesar de seu aumento não ter sido significante, apresentou uma grande tendência a aumentar, isto pode ser explicado ao aumento da gordura corporal, já que a massa magra, que praticamente contém toda água corpórea com eletrólitos e que apresentou uma diminuição não significante, é altamente condutiva apresentando baixa resistência.

Com o gráfico RXc-escore construído com elipses de $95 \%, 75 \%$ e $50 \%$ de tolerância, notou-se que após a PTX, houve um pequeno deslocamento dos pacientes da parte inferior esquerda (abaixo da elipse de $95 \%$ de tolerância) para a parte inferior direita (dentro das elipses de 95 e $75 \%$ de tolerância), isto é, houve uma diminuição da água corporal total, uma diminuição da massa celular e melhor distribuição da gordura corporal.

Assim, no presente estudo, tanto a análise dos componentes como a análise vetorial das propriedades da BIA, mostraram resultados semelhantes.

\subsection{Parâmetros bioquímicos}

\section{- Albumina, proteína total, uréia e creatinina}

Os parâmetros laboratoriais plasmáticos têm sido utilizados para avaliar e monitorar o estado nutricional de pacientes renais crônicos. Os métodos bioquimicos são mais sensiveis do que os antropométricos, e podem detectar problemas nutricionais mais precocemente ${ }^{105}$.

A albumina sérica é uma medida válida e clinicamente útil do estado nutricional de pacientes renais crônicos ${ }^{60}$. É a mais abundante das proteínas plasmáticas, mantém a pressão oncótica do plasma e transporta medicamentos, hormônios, enzimas e oligoelementos. A hipoalbuminemia significativa do ponto 
de vista clínico ocorre em diferentes tipos de desnutrição, e por essa razão, tornou-se parte rotineira da avaliação nutricional de pacientes hospitalizados e, posteriormente, de pacientes renais crônicos ${ }^{105}$.

Relatórios realizados pelo Health Care Financing Administration ${ }^{52}$, mostram que $43 \%$ dos pacientes com IRC em HD apresentam concentração sérica de albumina menor ou igual a $3,8 \mathrm{~g} / \mathrm{dl}$, e $35 \%$ menor que $3,5 \mathrm{~g} / \mathrm{dl}$.

Estudos têm identificado fatores de risco para o aumento da mortalidade e morbidade em pacientes com IRC. Entre estes, o estado nutricional é talvez o mais importante ${ }^{65}$. Lowrie \& Lew ${ }^{74}$, investigando fatores de risco de morte em pacientes em HD, observaram que baixo nível de albumina sérica é o mais potente indicador de mortalidade nestes pacientes. Mesmo a concentração plasmática estando entre 3,5 a $4,0 \mathrm{~g} / \mathrm{dl}$ (considerado valores normais para muitos laboratórios), resulta em um aumento relativo de risco para morte quando comparado com níveis acima de $4,0 \mathrm{~g} / \mathrm{dl}$.

Leavey et al. ${ }^{67}$, estudando a associação existente entre estado nutricional e morbidade e mortalidade em pacientes com IRC em HD, também concluíram que a albumina sérica é um preditor independente de risco de mortalidade nestes pacientes. Baixos níveis séricos de albumina refletem uma diminuição do depósito de proteína visceral, e desnutrição protéica. Desnutrição pode predispor pacientes em HD a complicações infecciosas que provocam, em grande proporção, mortes nesta população.

Kkajehdehi et al. ${ }^{63}$, comparando 15 pacientes com IRC em HD e HPT2 antes e $1,3,6$, e 12 meses após a PTX, verificaram que o nível sérico de albumina nestes pacientes não sofreu alteração significante após a PTX, porém, mesmo antes da PTX, os níveis de albumina plasmática eram maiores que 4,0 g/dl. Já Yasunaga et al. ${ }^{133}$, comparando 116 pacientes com IRC e HPT2, também antes e 1, 2, 3, 6 e 12 meses após a PTX, verificaram que tanto a albumina sérica como a proteína total aumentaram significantemente e gradualmente até os 12 meses depois da PTX.

Os achados de Yasunaga et al., são os mesmos encontrados no presente estudo, onde os níveis séricos de albumina e proteína total aumentaram 
significantemente após os 6 meses de PTX. A melhora destes parâmetros do estado nutricional, pode ter sido ocasionada pela correção dos níveis séricos de PTH, que indiretamente pode aumentar o catabolismo protéico.

O nível de creatinina sérica pré-diálise de pacientes em diálise crônica é proporcional à ingestão protéica e a massa somática (músculo-esquelética) ${ }^{60}$. Portanto, níveis séricos baixos de creatinina em pacientes em diálise crônica sem função renal residual, sugerem uma redução da massa muscular esquelética e/ou ingestão protéica deficiente. Em pacientes em HD, o risco de morte aumenta quando os níveis séricos de creatinina caem abaixo de $9-11 \mathrm{mg} / \mathrm{dl}^{74}$.

No presente estudo, os níveis séricos de creatinina não sofreram alterações estatisticamente significantes após a PTX, porém seus valores estão acima de $9 \mathrm{mg} / \mathrm{dl}$, mostrando então, que estes pacientes apresentam ingestão protéica e massa somática satisfatória.

Já a uréia sérica, que normalmente é utilizada como instrumento para medir a eficiência da diálise, também pode ser útil na monitorização da ingestão protéica atual do paciente ${ }^{105}$. Os valores desejáveis devem ser de 130 a 200 $\mathrm{mg} / \mathrm{dl}$ em pacientes renais, e neste estudo esteve diminuída tanto antes como após a PTX (de 127,5 $\pm 58,3 \mathrm{mg} / \mathrm{dl}$ foi para 99,1 $\pm 33,5 \mathrm{mg} / \mathrm{dl}$ ). Entretanto, a ingestão protéica destes pacientes estava dentro do recomendado para pacientes renais em $\mathrm{HD}$.

\section{- Proteina C reativa}

Recentes estudos têm mostrado o aumento nos níveis de marcadores inflamatórios em pacientes com IRC. Kimmel et al. ${ }^{65}$ mostraram que a concentração média da maioria das citoquinas inflamatórias permanece elevada nos pacientes em diferentes estágios da IRC quando comparado com indivíduos saudáveis. Vários laboratórios têm revelado aumento na concentração da proteína $C$ reativa (PCR) em 40 a $60 \%$ nos indivíduos com IRC em hemodiálise ${ }^{12}$. A PCR é um significante preditor de mortalidade e morbidade em pacientes em diálise ${ }^{12}$. 
O procedimento da hemodiálise está associado com a indução de cascatas catabólicas como o da síndrome da resposta sistêmica inflamatória, pelo aumento da concentração sérica da interleucina-6 (IL-6) e da sintese de fibrinogênio durante duas horas completas de hemodiálise ${ }^{12}$.

A inflamação crônica pode ocorrer devido a vários fatores em pacientes em hemodiálise, como: diminuição do clearence de citoquinas e acumulação de toxinas urêmicas (iPTH, leptina, etc.) devido a diminuição da função renal; fatores dialíticos como transferência de endotoxinas, catabolismo protéico, bioincompatibilidade do dialisato peritoneal e acesso vascular; presença de comorbidades incluindo infecções crônicas (doença peridontal, peritonite), diabetes mellitus, aterosclerose, e falência congestiva cardíaca ${ }^{12,87}$.

Yasunaga et al. ${ }^{133}$, comparando pacientes com IRC em diálise antes e após 01 ano da PTX, observaram que os parâmetros de imunidade humoral, representados por imunoglobulinas e complementos, melhoraram significantemente após a PTX.

Entretanto, no presente trabalho, não houve alteração significativa na concentração sérica da PCR após os 6 meses da PTX. Os altos valores da PCR presentes nestes pacientes podem ser atribuídos ao próprio procedimento hemodialítico, à ausência de função renal, e co-morbidades que possam estar presentes, e não aos elevados níveis séricos de iPTH, uma vez que não houve correlação entre iPTH e PCR.

\section{- Cálcio, fósforo e vitamina D}

A homeostasia do cálcio e fósforo está diretamente associada ao PTH e ao calcitriol (1,25-diidroxicolecalciferol), que é o metabólito ativo da vitamina $D$. Esses sistemas hormonais estão intimamente relacionados, e cada um interfere no outro por mecanismo de "feedback". O PTH aumenta o cálcio sérico por estímulo à mobilização de cálcio do osso e à absorção intestinal de cálcio, aumenta a síntese de calcitriol pelos rins, diretamente e como conseqüência do aumento da excreção de fósforo, resultando em diminuição do fósforo sérico. $O$ 
aumento de calcitriol por sua vez, inibe a secreção de PTH, que é o principal regulador da absorção intestinal de cálcio ${ }^{105}$.

Como já descrito anteriormente, a diminuição da função renal leva a alterações no balanço de cálcio, fósforo e no metabolismo da vitamina $D$, que são importantes tanto nas manifestações clínicas da uremia como no desenvolvimento do HPT2.

Antes da PTX, os pacientes deste estudo apresentavam niveis normais de cálcio sérico $(9,4 \pm 1,2 \mathrm{mg} / \mathrm{dl})$. Porém, após a realização da cirurgia, como era o esperado, os pacientes apresentaram hipocalcemia $(8,4 \pm 1,1 \mathrm{mg} / \mathrm{d})$, revelando que mesmo após 06 meses da PTX, a "fome óssea" continua presente, necessitando talvez, de uma maior ingestão de alimentos ricos em cálcio e de adequação na suplementação deste mineral.

Os niveis séricos de fósforo antes da PTX, estiveram como o descrito na literatura para pacientes com IRC e HPT2, sendo a hiperfosfatemia presente $(6,7 \pm 1,8 \mathrm{mg} / \mathrm{dl})$ antes da PTX. Após a cirurgia, os valores séricos de fósforo diminuíram para valores desejáveis $(4,5 \pm 1,5 \mathrm{mg} / \mathrm{dl})$. Nota-se, portanto, que antes da PTX, a hiperfosfatemia não estava muito acentuada ( $>7 \mathrm{mg} / \mathrm{d}$ ), podendo este fato ser atribuido em parte, a orientação nutricional dada aos pacientes, e principalmente a adesão dos pacientes à dieta pobre em fósforo.

Quanto à vitamina $D$, sabe-se que o nível sérico da $25(\mathrm{OH}) \mathrm{D}_{3}$, precursora da $1,25(\mathrm{OH})_{2} \mathrm{D}_{3}$, é o melhor indicador de deficiência, insuficiência, hipovitaminose, adequacidade e toxicidade da vitamina $D$ no organismo humano 16 .

Ghazali et al. ${ }^{47}$ estudando 113 pacientes com IRC em HD, observaram baixos níveis séricos de $25(\mathrm{OH}) \mathrm{D}_{3}(18,3 \mathrm{ng} / \mathrm{ml})$ nestes pacientes. Também observaram a presença de correlação negativa entre $\mathrm{OPTH}$ e a $25(\mathrm{OH}) \mathrm{D}_{3}$, portanto quanto maiores os niveis séricos de iPTH menores são as concentrações plasmáticas da vitamina $D$ em renais crônicos.

Estudos realizados na Comunidade Européia ${ }^{48,136}$, em amostra randomizada com 302 voluntários (149 mulheres e 153 homens), com $68 \pm 8$ anos de idade, mostraram que indivíduos com baixos niveis séricos de $25(\mathrm{OH}) \mathrm{D}_{3}$ 
apresentavam hiperparatireoidismo secundário. A prevalência de HPT2 mostrou uma inversa correlação com a concentração de $25(\mathrm{OH}) \mathrm{D}_{3}$, em contraste a concentração de $1,25(\mathrm{OH})_{2} \mathrm{D}_{3}$ não se correlacionou com a concentração de PTH. A prevalência de HPT2 foi particularmente alta em individuos com concentração de $25(\mathrm{OH}) \mathrm{D}_{3}<10 \mathrm{ng} / \mathrm{ml}$.

$\mathrm{Na}$ população do presente estudo, os níveis séricos de $25(\mathrm{OH}) \mathrm{D}_{3}$ não sofreram alteração estatisticamente significante após a PTX, e não houve correlação do $\mathrm{PTH}$ com a $25(\mathrm{OH}) \mathrm{D}_{3}$. A concentração da vitamina $\mathrm{D}$ apresentou-se acima de $30 \mathrm{ng} / \mathrm{ml}$ tanto antes como após a cirurgia.

Até o presente, concentrações de vitamina $D$ acima de $18-20 \mathrm{ng} / \mathrm{ml}$ são consideradas adequadas para indivíduos normais. Porém, o nível ótimo de vitamina $D$, seria aquele capaz de manter o PTH em níveis adequados ${ }^{85}$, assim a concentração ótima seria maior que $40 \mathrm{ng} / \mathrm{ml}$, e a seguinte classificação têm sido proposta:

- Hipovitaminose $D$ : concentrações entre 20 e $40 \mathrm{ng} / \mathrm{ml}$;

- Insuficiência de vitamina $D$ : concentração plasmática entre $10-20 \mathrm{ng} / \mathrm{ml}$;

- Deficiência de vitamina $D$ : concentrações acima abaixo de $10 \mathrm{ng} / \mathrm{ml}^{84}$.

Seguindo a classificação utilizada até o presente, os pacientes estudados apresentam niveis séricos "ótimos" da $25(\mathrm{OH}) \mathrm{D}_{3}$, tanto antes como após a PTX. Porém, utilizando a classificação acima descrita, os pacientes deste estudo apresentam hipovitaminose $D$ antes e após a PTX (de $30,1 \pm 15,5 \mathrm{ng} / \mathrm{ml}$ foi para 37,8 $\pm 20,7 \mathrm{ng} / \mathrm{ml}$ ). Mesmo assim, nossos pacientes apresentam níveis da $25(\mathrm{OH}) \mathrm{D}_{3}$ superiores aos niveis encontrados nos estudos realizados por Ghazali $(18,3 \mathrm{ng} / \mathrm{ml}$ ) e na Comunidade Européia (entre $10-18 \mathrm{ng} / \mathrm{ml}$ ).

Entretanto, a concentração sérica da $25(\mathrm{OH}) \mathrm{D}_{3}$ não depende apenas dos níveis séricos de PTH. Vários fatores influenciam sua concentração plasmática, como:

1. Fatores que afetam a síntese cutânea da vitamina $D$ sob a influência da radiação UVB. Esses fatores compreendem idade, concentração de melanina na pele, e condições de intensidade de exposição ao sol, como estação do ano, latitude, altitude e vestuário; 
2. Fatores nutricionais. Dietas ricas em vitamina D compreendem peixes crus e cozidos, leite e derivados;

3. A concentração da $25(\mathrm{OH}) \mathrm{D}_{3}$ circulante é modulada por fatores que afetam o metabolismo da vitamina $\mathrm{D}^{16}$.

A concentração da $25(\mathrm{OH}) \mathrm{D}_{3}$ em nossos pacientes pode ser explicada pelo primeiro fator descrito acima, já que a ingestão de leite e derivados, como descrito anteriormente, mostrou-se baixa, e que fatores que afetam o metabolismo da vitamina D estão presentes no HPT2.

\section{- Fosfatase alcalina total (FAt) e fração óssea (Fafo)}

O osso é um especializado tecido conectivo composto de células e uma matriz extracelular que tem a função de promover a calcificação, assim formando, em conjunto com a cartilagem, o sistema esquelético. Este metabolismo é caracterizado por dois processos opostos: formação e reabsorção. A formação depende dos osteoblastos, células ósseas responsáveis pela produção dos componentes da matriz óssea, e a reabsorção depende dos osteoclastos. $O$ equilíbrio destes dois processos irá determinar o ganho, perda ou balanço da massa óssea total ${ }^{129}$.

As doenças osteo-metabólicas são caracterizadas pela alteração do balanço de formação/reabsorção óssea. O HPT2 se caracteriza por um local ou difuso aumento da taxa de reabsorção óssea ${ }^{129}$. Para verificar a taxa de formação e/ou reabsorção óssea nestas doenças, marcadores séricos do metabolismo ósseo são utilizados na prática clínica com freqüência. Dentre os mais usados, e de menor custo, estão a Fosfatase Alcalina total (FAt) e sua fração óssea (FAfo).

A FAt é uma enzima encontrada em tecido hepático, intestinal, ósseo, renal, placentário e tumoral ${ }^{13,129}$. Apesar, de sua isoforma plasmática óssea (FAfo) ser mais sensivel que a fosfatase alcalina total (FAt) na avaliação da remodelação óssea de pacientes com IRC, a FAt sérica também é um bom indicador de reabsorção óssea ${ }^{13,127,129}$. Entretanto, Ureña et al. ${ }^{128}$ avaliando a aplicação de marcadores de turnover ósseo em pacientes com IRC e 
Osteodistrofia Renal, verificou que a FAfo sérica tem melhor correlação com o iPTH do que a FAt.

No presente estudo, não foi encontrada correlação entre a FAt e a FAfo com o iPTH, tanto antes como após a PTX.

Bervoets et al. ${ }^{9}$ avaliando o uso de marcadores bioquímicos no diagnóstico da Osteodistrofia Renal em pacientes com IRC em estágio final, observaram que a concentração sérica da FAfo e da FAt apresentavam-se altas nos pacientes diagnosticados com HPT2, e que a FAfo apresentava alta sensibilidade e especificidade no diagnóstico desta doença.

A FAfo é exclusivamente produzida pelos osteoblastos, e parece ser essencial no processo de mineralização e formação óssea ${ }^{129}$. Em pacientes adultos com IRC em HD, valores séricos de Fafo > $20 \mathrm{U} / \mathrm{l}$ são constantemente associados com os sinais biológicos e histológicos de HPT2 ou com alto turnover ósseo ${ }^{13}$.

Neste trabalho as concentrações plasmáticas da FAt e da FAfo antes da cirurgia apresentavam-se extremamente elevadas, o que é normal nesta patologia, já que se trata de uma doença de alta remodelação óssea ${ }^{129}$. Após a PTX a diminuição de seus valores foi estatisticamente significante, mesmo assim continuaram acima dos valores desejáveis, mostrando que, mesmo após os 6 meses de cirurgia a "fome óssea" ainda está presente.

\subsection{Paratormônio e estado nutricional}

Este trabalho teve como ponto relevante a correlação negativa entre PTH e a \% GC antes da cirurgia, refletindo o efeito catabólico que os elevados níveis contínuos de PTH exercem nestes pacientes.

Alguns trabalhos ${ }^{82,86}$ têm sugerido, que elevados níveis de PTH podem, de forma direta ou indireta, exercer uma ação tóxica sobre o metabolismo energético e principalmente protéico, promovendo catabolismo protéico e balanço nitrogenado negativo. Existem evidências sugerindo que o PTH pode ser uma toxina urêmica, isto porque muitas das manifestações da síndrome urêmica 
podem ser produzidas pelo excesso de PTH ${ }^{69,82,86,93,130}$. Alterações no metabolismo lipídico também são observadas com a elevação dos níveis de PTH, podendo levar a alterações no metabolismo muscular, inibindo a produção, transporte e utilização de energia ${ }^{104,126}$.

No presente estudo, a realização da PTX implicou melhora nos parâmetros bioquímicos do estado nutricional e do metabolismo ósseo dos pacientes avaliados.

Após a cirurgia, houve pequeno aumento na ingestão média de fósforo, talvez devido a maior ingestão de produtos lácteos (fonte de cálcio e fósforo), porém não houve alteração na ingestão de energia proveniente da dieta e na ingestão protéica.

Apesar do exposto, a diminuição dos niveis de PTH resultou em alterações importantes na composição corporal dos pacientes. Houve diminuição do volume hídrico com conseqüente alteração na massa magra e aumento na gordura corporal. Estes dados, somados ao aumento da albumina sérica, mostram a importância da realização da PTX para o estado nutricional de pacientes com IRC e HPT2.

Além disso, a orientação nutricional mostrou-se fundamental tanto no pré como no pós PTX, uma vez que alterações antropométricas importantes (aumento da gordura corporal e diminuição do volume hídrico) foram detectadas após 06 meses de remoção das glândulas paratireóides. 


\section{Conclusões}




\section{CONCLUSÕES}

Avaliação nutricional.

- Antes da cirurgia:

1. Os pacientes apresentaram ingestões de energia, proteína e fósforo de acordo com o preconizado pelo K/DOQI;

2. A ingestão de cálcio foi inferior ao mínimo recomendado;

3. Os pacientes apresentaram IMC médio normal, porém com distribuição inadequada entre os compartimentos de gordura, massa magra e água;

4. O PTH mostrou efeito negativo na gordura corporal.

- Após a cirurgia:

1. Não houve alteração nas ingestões alimentares;

2. Houve melhor distribuição da gordura corporal e diminuição da água corporal total;

3. Valores adequados de PTH não apresentaram correlação com a gordura corporal.

Marcadores bioquímicos, antes e após a cirurgia.

1. Os niveis de vitamina $D$ permaneceram adequados durante todo o estudo;

2. Não houve correlação do PTH com o estado inflamatório;

3. Houve melhora na remodelação óssea, com níveis de formação elevados no pós PTX;

4. Houve melhora na albumina sérica, importante preditor de morbimortalidade em renais crônicos. 


\section{Referências Bibliográficas}




\section{REFERÊNCIAS BIBLIOGRÁFICAS}

1 Agudelo MC. Factores que Inciden en el Estado Nutricional en los Pacientes en Tratamiento de Hemodiálisis. Lecturas Sobre Nutrición 1999; 6(2): 5557.

2 Ahmad KR, Kopple JD. Nutrition in maintenance hemodialysis patients. In: Kopple, JD, Massry SG. (eds). Nutritional Management of Renal Disease. New York: Williams \& Wilkins, 1997, p. 563-593.

3 Akizawa T, Fukagawa M. Modulation of parathyroid cell function by calcium ion in health and uremia. Am J Med Sci 1999; 317(6): 358-62.

4 Anção MS, Cuppari L, Tudisco ES, Draibe SA, Sigulem D. Versão 2.5: sistema de apoio e decisão em nutrição. São Paulo: Centro de Informática em Saúde da Universidade Federal de São Paulo/Escola Paulista de Medicina; 2000.

5 Avram MM, Mittman N, Myint MM, Fein P. Importance of low serum intact parathyroid hormone as a predictor of mortality in hemodialysis and peritoneal dialysis patients: 14 years of prospective observation. Am J Kidney Dis 2001; 38(6): 1351-1357. 
6 Baczynski R, Massry SG, Magott M, El-Belbessi S, Kohan R, Brautbar N. Effect of parathyroid hormone on energy metabolism of skeletal muscle. Kidney Int 1985; 28:722-727.

7 Bergström J, Kopple JD, Massry SG. Nutricional management of renal disease. J Uremic toxicity Baltimore: Williams \& Wilkins, 1997. p.97.

8 Bergström J, Lindholm B. Nutritional and adequacy of dialysis: How do hemodialysis and CAPD compare? Kidney Int 1993; 43(40): 39-50.

9 Bervoets ARJ, Spasovshi GB, Behets GT. Useful biochemical markers for diagnosing renal osteodystrophy in predialysis end-renal failure patients. Am J Kidney Dis 2003; 41(5): 997-1007.

10 Brown EM, Wilson RE, Eastman RC, Pallotta J, Marynick SP. Abnormal regulation of parathyroid hormone relese by calcium in secondary hyperparathyroidism due to chronic renal failure. J Clin Endocrinol Metab 1982; 54: 172-179.

11 Buzzard M. 24 hour dietary recall and food record methods. In Willet WC. Nutritional epidemiology. $2^{\circ}$ edition, New York, Oxford, Oxford University Press, 1998, p. 50-73.

12 Caglar K, Hakim RM, Ikizler TA. Approaches to the reversal of malnutrition, inflammation, and atherosclerosis in end-stage renal disease. Nutrition Rev 2002; 60(12): 378-387.

13 Calvo MS, Eyre DR, Gundberg CM. Molecular basis and clinical application of biological markers of bone turnover. Endocrine Rev 1996, 17(4): 333-368. 
14 Calvo MS. Dietary phosphorus, calcium metabolism and bone. J Nutr 1993; 123: $1627-1633$.

15 Calvo, MS. Dietary considerations to prevent loss of bone and renal function. Nutrition 2000; 16: 564-566.

16 Cannata-Andía JB, Alonso CG. Vitamin D deficiency: a neglected aspect of disturbed calcium metabolism in renal failure. Nephrol Dial Transplant 2002; 17: $1875-1878$.

17 Chamney PM, Krämer M, Rode C, Kleinekofort W, Wizemann V. A new technique for establishing dry weight in hemodialysis patients via whole body bioimpedance. Kidney Int 2002, 61: 2250-2258.

18 Chertow GM, Burke SK, Raggi P, for the Treat to Goal Working Group. Sevelamer attenuates the progression of coronary and aortic calcification in hemodialysis patients. Kidney Int 2002; 62: 245-252.

19 Chertow GM, Jacobs DO, Lazarus JM. Phase angle predicts survival in hemodialysis patients. J Ren Nutr 1997; 7:204-207.

20 Chertow GM. Nutritional assessment with bioelectrical impedance analysis in maintenance hemodialysis patients. J Am Soc Nephrol 1995; 6: 75-81.

21 Chumlea WC. Anthropometric assessment of nutritional status in renal disease. J Renal Nutr 1997; 7(4):176-181. 
22 Coburn JW, Hartenbower DL, Massry SG. Intestinal absorption of calcium and the effect of renal insufficiency. Kidney Int 1973; 4:96-104.

23 Cupisti A, Morelli E, D'Alessandro C, Lupetti S, Barsotti G. Phosphate control in chronic uremia: don't forget diet. J Nephrol 2003; 16: 29-33.

24 Cuppari L, Carvalho AB, Avesani CM, Kamimura MA, Lobão RRS, Draibe AS. Increased resting energy expenditure in hemodialysis patients with severe hyperparathyroidism. J Am Soc Nephrol 2004; 15: 2933-2939.

25 Cuppari L, Draibe AS, Anção MS, Sigulem D, Sustovich DR, Ajzen H, Ramos OL. Avaliação nutricional em pacientes renais crônicos em programa de hemodiálise. Estudo multicêntrico. Rev Ass Med Brasil 1989; 35(1): 9-14.

26 Cuppari L, Medeiros FAM, Pappini HF, Cendoroglo M, Martini L, Ajzen H, Draibe SA. Effectiveness of oral energy-protein supplementation in severely malnourished haemodialysis patients. J Renal Nutr 1994; 4(3): 127-135.

27 D'haese PC, Couttenye MM, De Broe ME. The diagnosis and tratment of aluminium-related bone disease: a comprehensive review. Nephrology Exchange $1994 ; 4:$ 12-19.

28 Davis GR, Zerwekh JE, Parker TF, Krejs GJ, Pak GY, Fordtran JS. Absorption of phosphate in the jejunun of patients with chronic renal failure before and after correction of vitamin D deficiency. Gastroenterology 1983; 85: 908-916. 
29 De Francisco ALM, Fresnedo GF, Rodrigo E, Piñera C, Amado JA, Arias M. Parathyroidectomy in dialysis patients. Kidney Int 2002; 61(80): 161-66.

30 Delmez JA, Slatopolsky E, Martin KJ, Gearing BN, Harter HR. Minerals, vitamin $\mathrm{D}$, and parathyroid hormone in continuous ambulatory peritoneal dialysis. Kidney Int 1982; 21: 862-867.

31 Denda M, Finch J, Slatoolsky E. Phosphorus accelerates the develoment of parathyroid hyerplasia and secondary hyperparathyroidism in rats with renal failure. Am J Kidney Dis 1996; 28(4): 596-602.

32 Drüeke TB, Zingraff J. The dilemma of parathyroidectomy in chronic renal failure. Curr Opin Nephrol Hypert 1994; 3: 386-395.

33 Drüeke TB. Control of secondary hyperparathyroidism by vitamin D derivatives. Am J Kidney Dis 2001, 37(suppl1,2): 58-61.

34 Drüeke TB. Medical management of secondary hyperparathyroidism in uremia. Am J Med Sci 1999; 317(6): 383-388.

35 Drüeke TB. Primary and secondy uremic hyperparathyroidism: from initial clinical observations to recent findings. Nephrol Dial Transplant 1998; 13: 1384-1387.

36 Drüeke TB. Renal osteodystrophy: management of hyperphosphataemia. Nephrol Dial Transplant 2000; 15 (5): 32-33. 
37 Drüeke TB. The pathogenesis of parathyroid gland hyperplasia in chronic renal failure. Kidney Int 1995; 48: 259-272.

38 Dumler F, Kilates C. Body composition analysis impedance in chronic maintenance dialysis patients: comparisons to the national Health and Nutrition Examination Survey III. J Renal Nutr 2003; 13(2): 166-172.

39 Dumler F, Kilates C. Use of bioelectrical impedance techniques for monitoring nutritional status in patients on maintenance dialysis. J Renal Nutr 2000; 10(3): 116-124.

40 Felsenfeld A, Llach F. Parathyroid gland function in chronic renal failure. Kidney Int 1993; 43: 771-789.

41 Ferreira MA. Diagnosis of renal osteodystrphy: when and how to use the biochemical markers and non-invasive methods; when bone biopsy is need. Nephrol Dial Transplant 2000; 15 (Suppl 15): S8-14.

42 Fidanza F, Kcarvonen MJ. Indices of relative weight and obesity. J Chronic Dis 1972; 25: 329-343.

43 Foster KR, Lukasky HC. Whole-body impedance. What does is measure? Am J Clin Nutr 1996; 64: 388-396.

44 Fournier A, Oprisiu R, Hottelart C, Yverneau PH, Ghazali A, Atik A, et al. Renal osteodystrophy in dialysis patients: diagnosis and treatment. Artificial Organs 1998; 22: 530-557. 
45 Fukagawa M, Tominaga Y, Kitaoka M, Kakuta T, Kurokawa K. Medical and surgical aspects of parathyroidectomy. Kidney Int 1999; 56 (73): 65-69.

46 Fukuda N, Tanaka H, Fukagawa M, Kurokawa K, Seino Y. Decreased 1,25Dihydroxyvitamin D3 Receptor Density in associated with a more severe form of parathyroid hyperplasia in chronic uremic patients. J Clin Invest 1993; 92: 1436-43.

47 Ghazali A, Fardellone P, Pruna A, Atik A, Achard JM, Oprisiu R, et al. Is low plasma 25- $(\mathrm{OH})$ vitamin $D$ a major risk factor for hyperparathyroidism and Looser's zones independent of calcitriol? Kidney Int 1999; 55: 2169-2177.

48 Gómez C, Navez ML, Fernandez JL. Vitamin D levels and prevalence of secondary hyperparathyroidism in a spanish population - based sample aged 54 to 89. J Bone Miner Res 2001; 16: 156.

49 Goodman WG, Coburn JW, Slatoplosky E, Salusky IB. Renal Osteodystrophy in Adults and Children. In Favus MJ. Primer on the Metabolic Bone Disease and Disorders of Mineral Metabolism, Third Edition, Chicago, Illinois, Lipincott - Raven, 1996, p. 341-360.

50 Gueiros JEB, Chammas MC, Gerhard R, Boilesen CFDS, Oliveira IRS, Moysés RMA, Jorgetti V. Percutaneous ethanol (PEIT) and calcitrol (PCIT) injection therapy are ineffective in treating severe secondary hyperparathyroidism. Nephrol Dial Transplant 2004; 19(3): 657-663. 
51 Haklar G, Yegenaga I, Yalcin, AS. Evaluation of oxidant stress in chronic hemodialysis patients: use of different parameters. Clin. Chim. Acta. 1995; 234:109-114.

52 Health Care Financing Administration. 1999 Annual Report, ESRD Clinical Performance Measures Project. Baltimore, MD, Departament of Health and Human Services, 1999.

53 Hernández A, Concepción MT, Rodríguez M, Salido E, Torres A. High phosphorus diet increases preproPTH mRNA independent of calcium and calcitriol in normal rats. Kidney Int 1996; 50: 1872-1878.

54 Higgins RM, Richardson AJ, Ratcliffe PJ, Woods CG, Oliver DO, Morris PJ. Total parathyroidectomy alone or with autograft for renal hiperparathyroidism? Qj Med 1991; 79(288): 323-332.

55 Hou SH, Zhao J, Ellman CF. Calcium and phosphorus fluxes during hemodialysis with low-calcium dialysate. Am J Kidney Dis 1991; 18: $217-$ 224.

56 Hruska KA \& Teitelbaum SL. Renal Osteodystrophy. New Engl J Med 1995; 333: 166-174.

$57 \mathrm{Hsu} \mathrm{CH}$. Historical perspective on management of calcium and phosphorus metabolism in chronic renal failure. Am J Kidney Dis 2001; 37(1): 195-201. 
58 Johansen KL, Kaysen GA, Young BS, Hung AM, Silva M, Chertow GM. Longitudinal study of nutritional status, body composition, and physical function in hemodialysis patients. Am J Clin Nutr 2003; 77: 842-846.

59 Júnior Romão JE. Insuficiência Renal Crônica. In: Cruz J, Praxedes JN, Cruz HMM. Nefrologia. São Paulo: Sarvier, 1994. P.187-200.

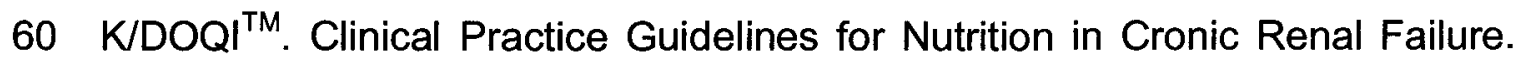
Am J Kidney Dis 2000; 35(suppl 2): S17-18.

61 Kamimura MA, Santos NSJ, Avesani CM, Canziani MEF, Draibe SA, Cuppari L. Comparison of three methods for the determination of body fat in patients on long-term hemodialysis therapy. J Am Diet Assoc 2003; 103: 195-199.

62 Kaysen GA, Eiserich JP. Characteristics and effects of inflammation in endstage renal disease. Seminars in Dialysis 2003; 16(6): 438-446.

63 Khajehdehi P, Ali M, Al-Gebory F, Henry G, Bastani B. The effects of parathyroidectomy on nutritional and biochemical status of hemodialysis patients with severe secondary hyperparathyroidism. J Renal Nutr 1999; 9 (4): 186-191.

64 Kilav R, Silver J, Naveh-Many T. Parathyroid hormone gene expression in hypophosphatemic rats. J Clin Invest 1995; 95: 327-333.

65 Kimmel PL, Phillips TM, Simmers SJ. Immunologic function and survival in hemodialysis patients. Kidney Int 1998, 54: 236-244. 
66 Kuczmarski RJ. Bioeletrical impedance analysis measurements as part of a national nutrition survey. Am J Clin Nutr 1996; 64(suppl): S453.

67 Leavey SF, Strawderman RL, Jones CA, Port FK, Held PJ. Simple nutritional indicators as independent predictors of mortality in hemodialysis patients. Am J Kidney Dis 1998; 31(6): 977-1006, 1998.

68 Lewin S, Gouveia CHA, Marone MMS, Wehba S, Malvestiti LF, Bianco AC. Densidade mineral óssea vertebral e femoral de 724 mulheres brancas brasileiras: influência da idade e do peso corporal. Rev Assoc Med Bras 1997; 43(2): 134-139.

69 Liang K, Oveisi F, Vaziri ND. Role of hyperparathyroidism in the genesis of hypertriglyceridemia and VLDL receptor deficiency in chronic renal failure. Kidney Int 1998; 53: 620-630.

70 Liu SH \& Chu HI. Studies of calcium and phosphorus metabolism with special reference to pathogenesis and affects of dihydrotachysterol and iron. Medicine 1943; 2: 102-161.

71 Llach F \& Bover J. Renal Osteodystrophy. In Brenner BM. In The Kidney, Five edition, Philadelphia, Pennsylvania, WB Saunders Company, 1996, p. 2187-2273.

72 Llach F, Massry SG. On the mechanism of secondary hyperparathyroidism in moderate renal insufficiency. J Clin Endocrinol Metab 1985; 61: 601-606. 
73 Locatelli F, Cannata-Andia JB, Drüke TB, Hörl WH, Fouque D, Heimburguer $\mathrm{O}$, Ritz E. Management of disturbances of calcium and phosphate metabolism in chronic renal insufficiency, with emphasis on the control of hyperphosphataemia. Nephrol Dial Transplant 2002; 17: 723-731.

74 Lowrie EG, Lew NL. Death risk in hemodialysis patients: the predictive value of commonly measured variables and an evaluation of death rate differency between facilities. Am J Kidney Dis 1990; 15: 458-482.

75 Lukaski HC, Bolonchuk WW, Hall CB, Siders W. Validation of tetrapolar bioeletrical impedance method to assess human body composition. J Appl Physiol 1986; 60(4): 1327-1332.

76 Maggiori Q, Nigrelli S, Ciccarelli C. Nutritional and prognosis correlates of bioimpedance indexes in hemodialysis patients. Kidney Int 1996; 50: 21032108.

77 Malberti F, Corradi B, Pagliari B, Romanini D, Gazo A, Sidol A, et al. The sigmoidal parathiroid hormone-ionized calcium curve and the set point of calcium in hemodialysis and continuous ambulatory peritoneal dialysis. Perit Dial Int 1993; 13(2): 476-479.

78 Malberti F, Marcelli D, Ferruccio C, Limido A, Spotti D, Locatelli F. Parathyroidectomy in patients on renal repalcement therapy: An epidemiologic study. J Am Soc Nephrol 2001; 12: 1242-1248. 
79 Mans B, Stevens L, Miskulin D, Owen WFJr, Winkelmayer WC, Tonelli M. A systematic review of sevelamer in ERSD and an analysis of its potential economic impact in Canada and the United States. Kidney Int 2004; 66(3): 1239-1247.

80 Martin CJ, Reams SM. The renal dietitian's role in mamaging hyperphosphatemia and secondary hyperparathyroidism in dialysis patients: a national survey. J Renal Nutr 2003; 13(2): 133-136.

81 Martin KJ, González EA. Strategies to minimize bone disease in renal failure. Am J Kidney Dis 2001; 38(6): 1430-36.

82 Massry SG. Is PTH a uremic toxin? Nephron 1977; 19:125-130.

83 Máttar JA. Bioimpedância, reatância e resistência: parâmetros bio-físicos úteis em suporte nutricional e medicina intensiva. R Metab Nutr 1995; 2: 5862.

84 McKenna MJ, Freaney R. Secondary hyperparathyroidism in the elderly: means to definig hypovitaminosis D. Osteoporos Int 1998; 8: 3-6.

85 Meunier PJ. Vitamin D Insufficiency: Reappraisal of its Definition. Threshold and Bone Consequences. In: Benckhardt $P$, Pawson-hughes $B$, Heaney RP. Nutritional Aspects of Osteoporosis. San Diego: Academic Press, 2001. p.167-172. 
86 Miroslaw S, Grazina P, Peggy R, Borum G, Shaul G, Massry SG. Chronic renal failure, parathyroid hormone and fatty acids oxidation in skeletal muscle. Kidney Int 1988; 33: 555-560.

87 Mitch WE. Getting beyond cross-sectional studies of abnormal nutritional indexes in dialysis patients. Am J Clin Nutr 2003; 77: 760-761.

88 Monteiro JBR, Silva RR, Rosado EL, Gouveia MG, Norfino SP. Uso da bioimpedância elétrica e pregas cutâneas em pacientes submetidos a hemodiálise. Rev Bras Nutr Clin 1999; 14: 220-227.

89 Montenegro FLM. Paratireoidectomia total com ou sem autotransplante no tratamento do hiperparatireoidismo secundário. São Paulo; 2000. [Tese de Doutorado - Faculdade de Medicina- USP].

90 Mucsi I, Hercz G, UldallR, Ouwendyk M, Francouer R, Pierratos A. Control of serum phosphate whithout any phosphate binders in patients treated with nocturnal hemodialysis. Kidney Int 1998; 53:1399-1404.

91 Navez ML, Alvarez D, Gómez C. Prevalence of secondary hyperparathyroidism (HPT) in a spanish population - based sample aged 54 to 89. Necessity to redifine normal values of 25-hydroxyvitaminD (25OHD). J Am Soc Nephrol 2001; 12: 769. 
92 National Kidney Foundation. K/DOQI Clinical Practice Guidelines for Bone Metabolism and Disease in Chronic Kidney Disease. Am J Kidney Dis 2003; 42 (suppl3): S1-S202.

93 Nishizawa $\mathrm{Y}$, Shoji T, Kawagishi T, Mori $H$. Atherosclerosis in uremia: Possible roles of hyperparathyroidism and intermediate density lipoprotein accumulation. Kidney Int 1997; 62: 90-92.

94 Nogueira PCK, Carvalhaes JTA. Insuficiência Renal Crônica. Ciência Hoje 1994, 18(105): 38-50.

95 Oldham NM. Overview of bioeletrical impedance analyzers. Am J Clin Nutr 1996; 64: 405-412.

96 Oldrizzi L, Rugio C, Maschio G. The verona experience on the effect of diet on progressiom of renal failure. Kidney Int 1989; 36 (suppl. 27): S103.

97 Ott M, Fischer $\mathrm{H}$, Polat $\mathrm{H}$. Bioelectrical impedance analysis as a predictor of survival in patients with humam immunodeficiency virus infection. J Acquir Immune Defic Syndr 1995; 9: 20-25.

98 Parfitt AM. The hyperparathyroidism of chronic renal failure: a disorder of growth. Kidney Int 1997; 52: 3-9. 
99 Peters BSE, Jorgetti V, Martini LA. Influência do hiperparatireoidismo secundário grave no estado nutricional de pacientes com insuficiência renal crônica. Rev Bras Nutr Clin 2004, inpress.

100 Piccoli A, Nescolarde LD, Rosell J. Análisis convencional y vctorial de bioimpedancia em la práctica clínica. Nefrologia 2002; 22(3): 228-238.

101 Piccoli A, Pastori G. BIVA Software. Departament of Medical and Surgical Sciences, University of Padova, Italy, 2002.

102 Piccoli A, Pillon L, Dumler F. Impedance vector distribution by sex, race, body mass index, and age in the United States: standard reference intervals as bivariate $Z$ scores. Nutrition 2002; 18: 153-167.

103 Piccoli A, Pillon L, Favaro E. Asymmetry of the total body water prediction bias using the impedance index. Nutrition 1997; 13: 438-441.

104 Rezende LTT, Cuppari L, Carvalho AB, Canziani MEF, Manfredi SR, Cenderoglo M, Sigulem DM, Draibe SA. Nutritional status of hemodialysis patients with secondary hyperparathyroidism. Braz J Med Biol Res 2000; 33(11):1305-13011.

105 Riella MC, Martins C. Avaliação e Monitoração do Estado Nutricional em Pacientes Renais. In: Riella MC, Martins C. Nutrição e o Rim. Rio de Janeiro: Guanabara Koogan, 2001. p. 83-90. 
106 Rudolph JL. RJL Systems Cyprus1.2 C Body Composition Analysis. USA, 1991.

107 Salem MM. Hyperparathyroidism in the hemodialysis population: A survey of 612 patients. Am J Kidney Dis 1997; 29: 862-865.

108 Sampaio da Cruz EA, Lugon JR. Revisão/Atualização em diálise: prevenção e tratamento da osteodistrofia renal. J Bras Nefrol 1996; 18(3): 295-301.

109 Sesso R, Ferraz MB. Avaliação crítica do Sevelamer no tratamento da hiperfosfatemia em pacientes com insuficiência renal crônica. Rev Assoc Med Bras 2003; 49(1): 103-108.

110 Sherrard D, Ott S, Maloney N, Andress D, Coburn J. Uremic osteodystrophy: Classification, cause and treatment. In: Frame, B. \& Potts, J.T.JR., ed. Clinical Disorders of Bone and Mineral Metabolism. Amsterdam, Expecta Medica, 1983, p. 254-59.

111 Silver J, Kilav R, Naveh-Many T. Mechanisms of secondary hyperparathyroidsm. Am J Physiol Renal Physiol 2002; 283:367-376.

112 Silver J, Sela SB, Naveh-Many T. Regulation of parathyroid cell proliferation. Curr Opin Nephrol Hypert 1997; 6: 321-326. 
113 Silver J, Yalcindag C, Sela-Brown A, Kilav R, Naveh-Many T. Regulation of the parathyroid hormone gene by vitamin $D$, calcium and phosphatate. Kidney Int 1999; 56(73): 2-7.

114 Slatopolsky E, Brown A, Dusso A. Pathogenesis of secondary hyperparathyroidism. Kidney Int 1999; 56(73): 14-19.

115 Slatopolsky E, Brown A, Dusso A. Role of phosphorus in the pathogenesis of secondary hyperparathyroidism. Am J Kidney Dis 2001, 37(suppl1,2): S5457.

116 Slatopolsky E, Delmez JA. Pathogenesis of secondary hyperparathyroidism. Am J Kidney Dis 1994; 23(2): 229-36.

117 Slatopolsky E, Dusso A, Brown A. The role of phosphorus in the development of secondary hyperparathyroidism and parathyroid cell proliferation in chronic renal failure. Am J Med Sci 1999; 317: 370-376.

118 Slatopolsky E, Finch J, Denda M, Macdonald PN, Dusso A, Brown A. Phosphorus restriction prevents parathyroid gland growth. J Clin Invest 1996; 97: 2534-2540.

119 Slatopolsky E. The role of calcium, phosphorus and vitamin D metabolism in the development of secondary hyperparathyroidism. Nephrol Dial Transplant $1997 ; 13(3): 3-8$. 
120 Sociedade Brasileira de Nefrologia. Censo 2003/2004. São Paulo, SP: 2004.

121 Sugano LK. Paratireoidectomia total e autotransplante no tratamento do hiperparatireoidismo secundário. Estudo de oito casos. São Paulo; 1999. [Dissertação de Mestrado - Faculdade de Ciências Médicas da Santa Casa de São Paulo].

122 Tatsumi S, Segawa H, Morita K, Haga H, Yamamoto $H$, Inoue $Y$, et al. Molecular cloning and hormonal regulation of PiT-1, a sodium-dependent phosphate cotransporter from rat parathyroid glands. Endocrinology 1998; 139: 1692-1699.

123 Tominaga Y, Uchida K, Haba T, Katayama A, Sato T, Hibi Y, et al. More than 1000 cases of total parathyroidectomy with foreman autograft for renal hyperparathyroidism. Am J Kidney Dis 2001, 38(4) Suppl 1: S168-171.

124 Tominaga $Y$. Surgical management of secondary hyperparathyroidism in uremia. Am J Med Sci 1999; 317(6): 377-382.

125 Tompson FE, Byers T. Dietary assessment resource manual. J Nutr 1994; 124(5): 2301-2345.

126 Tzano-Martins C, Futata E, Jorgetti V, Duarte AJ. Immune response in hemodialysis patients: Is there any difference when low and hight IPTH levels are compared? Clin Nephrol 2000; 54: 22-29. 
127 Ureña P, Ferreira A, Kung VT. Serum pyridinoline as a specific marker of collagen breakdown and bone metabolism in hemodialysis patients. $\mathbf{J}$ Bone Min Dis 1995; 10(6): 932-939.

128 Ureña P, Hruby M, Ferreira A, Ang K, Vernejoul M. Plasma total versus bone alkaline phosphatase as marker of boné turnover in hemodialysis patients. $J$ Am Soc Nephrol 1996; 7: 506-512.

129 Ureña P, Vernejoul MC. Circulating biochemical markers of bone remodeling in uremic patients. Kidney Int 1999; 55: 2141-2156.

130 Vaziri ND, Wang XQ, Liang K. Secondary hyperparathyroidism dowregulates liporotein lipase expression in chronic renal failure. Am J Physiol 1997; 273:925-930.

131 Woodrow G, Oldroyd B, Smith MA, Turney JH. Measurement of body composition in chronic renal failure: comparison of skinfold anthropometry and bioelectrical impedance with dual energy X-ray absorptiometry. Eur J Clin Nutr 1996; 50: 295-301.

132 World Health Organization. Physical status: the use and interpretation of anthropometry. Geneva, 1995 (WHO Technical Report Series 854). 
133 Yasunaga C, Nakamoto M, Matsuo K, Nishihara G, Yoshida T, Goya T. Effects of a Parathyroidectomy on the Immune System in Nutritional Condition in Chronic Dialysis Patients with Secondary Hyperparathyroidism. Am J Surgery 1999, 178: 332-336.

134 Yeun JY, Levine RA, Mantadilok V, Kaysen GA. C-reactive protein predicts all-cause and cardiovascular mortality in hemodialysis patients. Am J Kidney Dis 2000; 35: 469-479.

135 Zambon MP, Belangero VMS, De Britto ACG, Morcillo AM. Avaliação do Estado Nutricional de Crianças e Adolescentes com Insuficiência Renal Crônica. Rev Assoc Med Bras 2001; 47(2): 137-140.

136 Zittermann A. Vitamin $D$ in preventive medicine: are we ignoring the evidence? Brit J Nutr 2003; 89: 552-572. 
Anexos 


\section{ANEXOS}

\section{Anexo 1- Termo de consentimento}

Eu, voluntariamente, participarei da pesquisa intitulada: "Acompanhamento e Avaliação Nutricional em Pacientes com Insuficiência Renal Crônica e Hiperparatireoidismo Secundário Submetidos a Paratireoidectomia", sob responsabilidade de Bárbara Santarosa Emo Peters.

Fui esclarecido que:

- O objetivo da pesquisa é o de comparar o estado nutricional de pacientes com insuficiência renal crônica e hiperparatireoidismo secundário, antes e após a realização da paratireoidectomia;

- Fornecerei informações sobre minha alimentação, para apenas ser avaliada, e para receber uma orientação dietética adequada;

- Realizarei exames bioquímicos, e que para o qual serão necessários $10 \mathrm{ml}$ de sangue, sendo que todo o material utilizado será descartável;

- Realizarei exames antropométricos feitos pela própria nutricionista, como peso, altura, pregas cutâneas (triciptal, biciptal, subescapular e suprailíaca), circunferência do braço e do punho, e bioimpedância elétrica;

- Os exames bioquímicos e antropométricos serão realizados 1 semana antes e 6 meses após a paratireoidectomia;

- Esta pesquisa não trará nenhum risco à minha saúde;

- As informações obtidas são sigilosas, e somente serão divulgadas nos meios científicos os valores médios e totais observados, não havendo identificação dos participantes;

- Tenho a liberdade de não colaborar ou de desistir a qualquer momento ao longo da pesquisa, não tendo este ato, nenhuma conseqüência ao meu tratamento médico;

- Em caso de dúvidas ou maiores esclarecimentos, fui informado que poderei entrar em contato com a nutricionista responsável Bárbara Santarosa Emo Peters pelo telefone (11) 3731-7185.

Ciente,

Assinatura do participante

São Paulo 
Anexo 2- Formulário de Registro Alimentar

REGISTRO ALIMENTAR - DIÁRIO DE TRÊS DIAS

NOME :

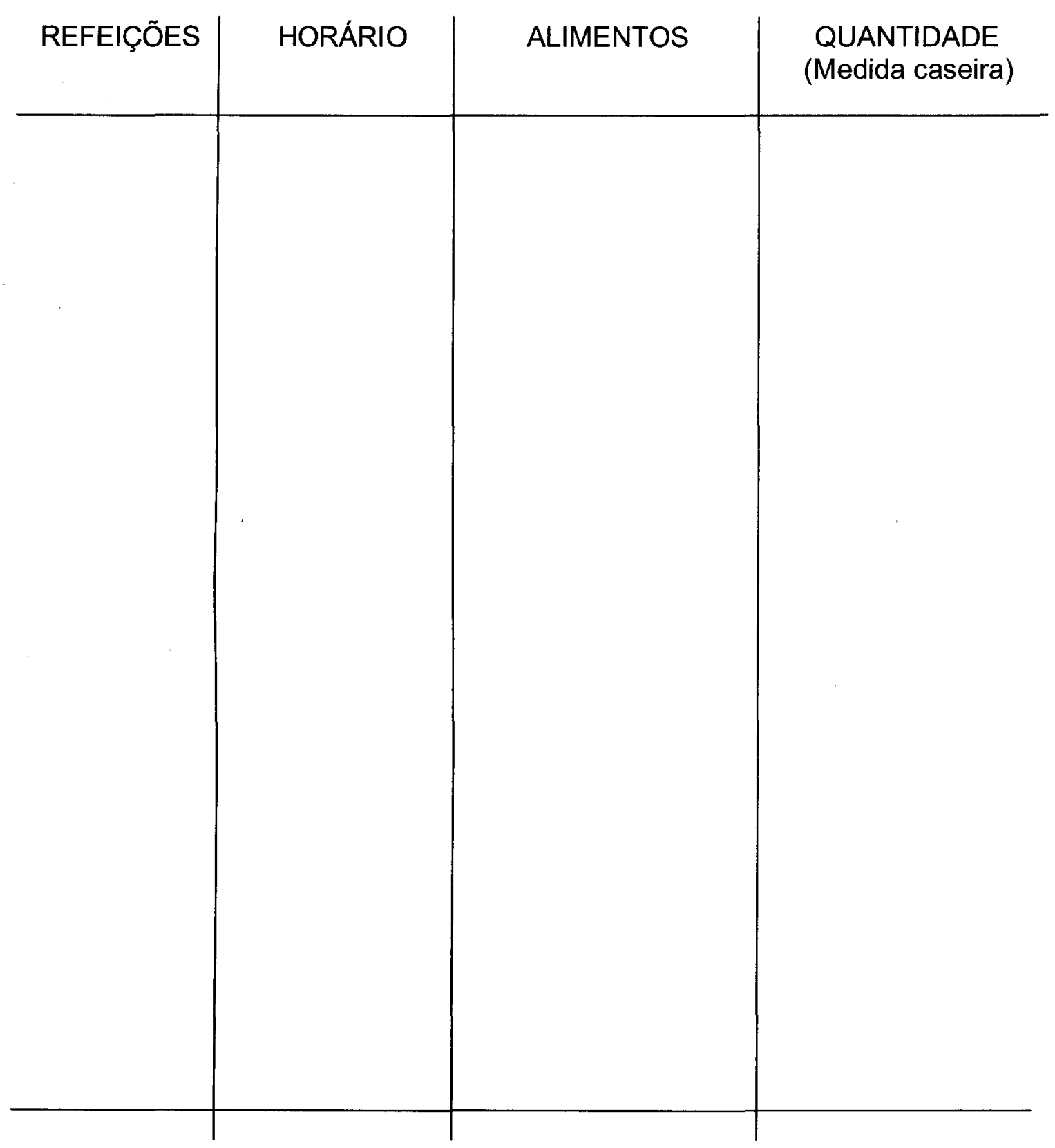

DATA: DIA DA SEMANA: 
III

Anexo 3 - Aprovação do projeto de pesquisa pelo COEP

Anexos 


\section{Universidade de São Paulo \\ Faculdade de Saúde Pública \\ COMITE DE ÉTICA EM PESQUISA - COEP}

Av. Dr. Arnaldo, 715 - CEP 01246-904 - São Paulo - Brasil

Telefones: (55-11) 3066- 7734 - fone/fax (55-11) 3064 -7314 -

\section{Of.COEP/203/02}

28 de junho de 2002

Pelo presente, informo que o Comitê de Ética em Pesquisa da Faculdade de Saúde Pública da Universidade de São Paulo-COEP, analisou e aprovou "adreferendum", de acordo com os requisitos da Resolução CNS/196/96, o Protocolo de Pesquisa n. ${ }^{\circ}$ 824, intitulado: "AVALIAÇÃO E ACOMPANHAMENTO NUTRICIONAL DE PACIENTES COM INSUFICIÊNCIA RENAL CRÔNICA E HIPERPARATIREOIDISMO SECUNDÁRIO SUBMETIDOS A PARATIREOIDECTOMIA", apresentado pela pesquisadora Bárbara Santarosa Emo Peters.

Atenciosamente,

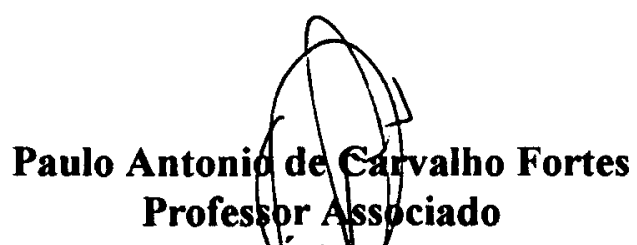

Coordenador do Comitê de ticham Pesquisa da FSP-COEP 